\title{
DOE/NE/32180-TI
}

\section{NUCLEAR SPACE POWER SAFETY AND \\ FACILITY GUIDELINES STUDY}

(SEPTEMBER 1995) 


\section{NUCLEAR SPACE POWER SAFETY \\ AND \\ FACILITY GUIDELINES STUDY \\ (11 September 1995)}

Prepared for:

Department of Energy

Office of Procurement Assistance

and

Program Management HR-522.2

Washington, D.C. 20585

by:

William F. Mehlman

The Johns Hopkins University Applied Physics Laboratory

Johns Hopkins Road Laurel, Maryland 20723-6099

in response to:

Department of Energy grant to

The Johns Hopkins University Applied Physics Laboratory DE-FG01-94NE32180 dated 27 September 1994

\section{DISCLAIMER}

This report was prepared as an account of work sponsored by an agency of the United States Government. Neither the United States Gnvernment nor any agency thereof, nor any of their employees, makes any warranty, express or implied, or assumes any legal liability or responsibility for the accuracy, completeness, or usefulness of any information, apparatus, product, or process disclosed, or represents that its use would not infringe privately owned rights. Reference herein to any specific commercial product, process, or service by trade name, trademark, manufacturer, or otherwise does not necessarily constitute or imply its endorsement, recommendation, or favoring by the United States Government or any agency thereof. The views and opinions of authors expressed herein do not necessarily state or reflect those of the United States Government or any agency thereof. 


\section{DISCLAMMER}

Portions of this document may be illegible in electronic image products. Images are produced from the best available original document. 


\section{TABLE OF CONTENTS}

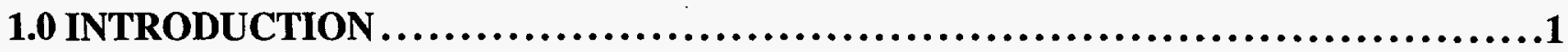

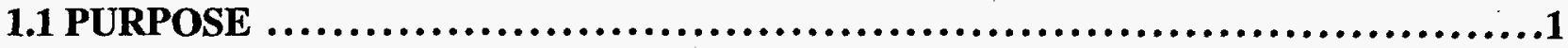

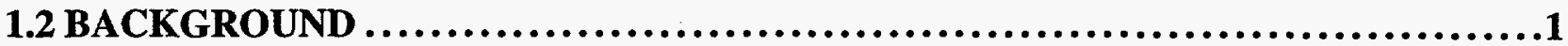

1.3 SCOPE....................................................................

2.0 NUCLEAR SPACE SAFETY GUIDELINES AND CONSIDERATIONS..............3



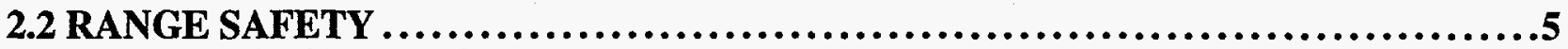

2.2.1 TRANSPORTATION AND HANDLING OF NUCLEAR FUEL $\ldots \ldots \ldots \ldots \ldots \ldots \ldots .6$



2.2.3 LAUNCH PAD AND EXPLOSION ACCIDENTS $\ldots \ldots \ldots \ldots \ldots \ldots \ldots \ldots \ldots \ldots \ldots \ldots \ldots 7$

2.2 .4 CONTINGENCY PLANS....................................................7

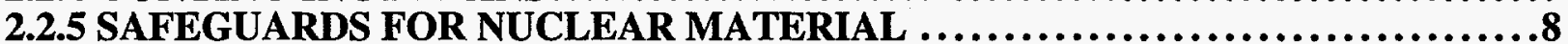

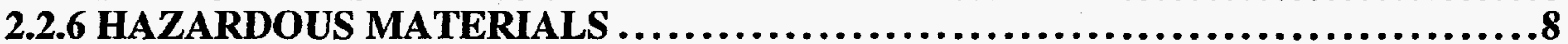

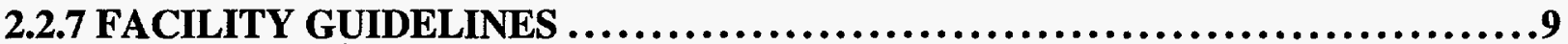

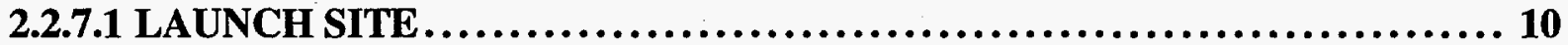

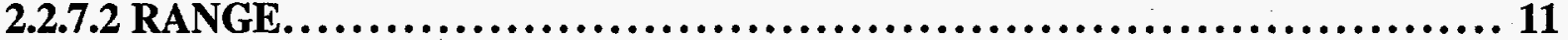

2.2.7.3 FACILITIES $\ldots \ldots \ldots \ldots \ldots \ldots \ldots \ldots \ldots \ldots \ldots \ldots \ldots \ldots \ldots \ldots \ldots \ldots \ldots \ldots \ldots \ldots \ldots \ldots, 11$

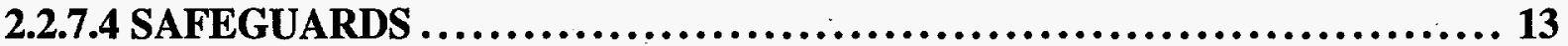







2.3.3 RADIOLOGICAL RELEASE TO THE SPACE ENVIRONMENT ............. 16

2.3.4 REACTOR SHUT-DOWN / ON-ORBIT DISPOSAL . ..................... 16

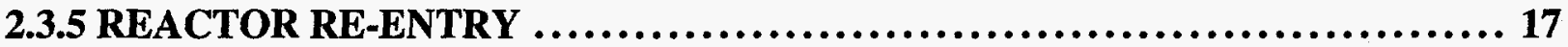

2.3.6 INTERFERENCE WITH OTHER SPACE MISSIONS $\ldots \ldots \ldots \ldots \ldots \ldots \ldots \ldots \ldots, 18$

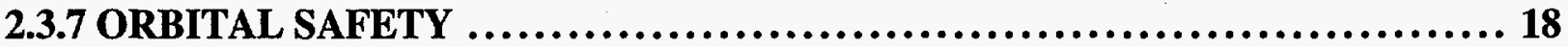

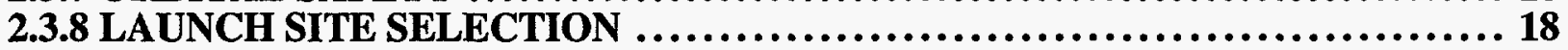



2.4.1 INTERAGENCY NUCLEAR SAFETY REVIEW PANEL (INSRP) .......... 19

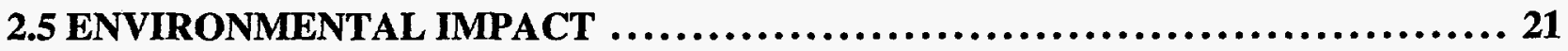

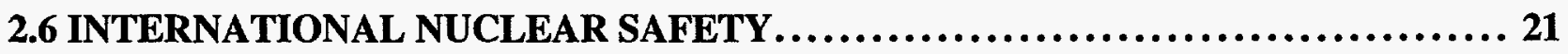



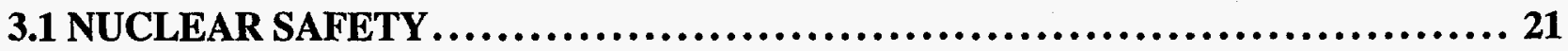

3.2 RANGE SAFETY AND RANGE OPERATIONS $\ldots \ldots \ldots \ldots \ldots \ldots \ldots \ldots \ldots \ldots \ldots \ldots, 22$

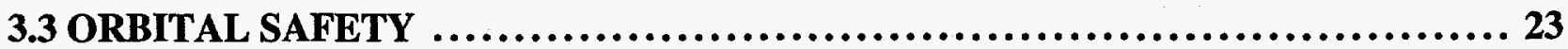




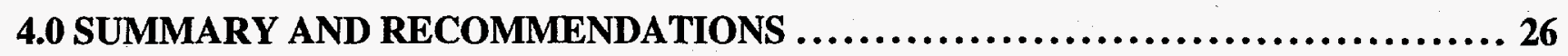

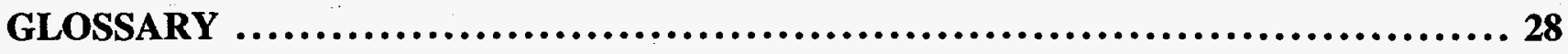

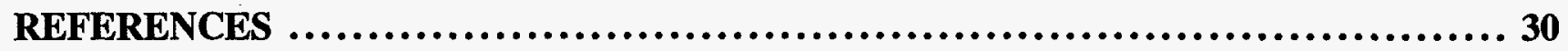

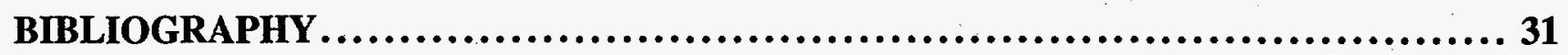

\section{LIST OF FIGURES}

FIGURE 1: EXAMPLE SAFETY ORGANIZATION $\ldots \ldots \ldots \ldots \ldots \ldots \ldots \ldots \ldots \ldots \ldots \ldots . \ldots$ FIGURE 2: APPROXIMATE ORBIT LIFETIME AS A FUNCTION OF ALTITUDE...... 15 FIGURE 3: APPROXIMATE RADIOACTIVE DECAY AS A FUNCTION OF TIME..... 16 FIGURE 4: SPACE NUCLEAR SAFETY REVIEW \& APPROVAL PROCESS .......... 20 FIGURE 5: NOMINAL SAFETY REVIEW AND APPROVAL SCHEDULE $\ldots \ldots \ldots \ldots \ldots 24$

\section{LIST OF TABLES}

TABLE 1: SUMMARY OF SPACE NUCLEAR POWER SYSTEMS LAUNCHED BY U.S...1 TABLE 2: REACTOR RE-ENTRY ISSUES MATRIX $\ldots \ldots \ldots \ldots \ldots \ldots \ldots \ldots \ldots \ldots \ldots \ldots \ldots$

TABLE 3: REACTOR RE-ENTRY ISSUES MATRIX $\ldots \ldots \ldots \ldots \ldots \ldots \ldots \ldots \ldots \ldots \ldots \ldots \ldots$

TABLE 4: TYPICAL LIST OF NUCLEAR SAFETY RELATED DOCUMENTS........ 25 


\section{0}

INTRODUCTION

This report addresses safety guidelines for space nuclear reactor power missions and was prepared by The Johns Hopkins University Applied Physics Laboratory (JHU/APL) under a Department of Energy grant, DE-FG01-94NE32180 dated 27 September 1994. This grant was based on a proposal submitted by the JHU/APL in response to an "Invitation for Proposals Designed to Support Federal Agencies and Commercial Interests in Meeting Special Power and Propulsion Needs for Future Space Missions" (Federal Register, Vol. 58, No. 231, 3 December 1993).

The United States has not launched a nuclear reactor since SNAP 10A in April 1965 although many Radioisotope Thermoelectric Generators (RTGs) have been launched. An RTG powered system is planned for launch as part of the Cassini mission to Saturn in 1997. Recently the Ballistic Missile Defense Office (BMDO) sponsored the Nuclear Electric Propulsion Space Test Program (NEPSTP) which was to demonstrate and evaluate the Russian-built TOPAZ II nuclear reactor as a power source in space. As of late 1993 the flight portion of this program was canceled but work to investigate the attributes of the reactor were continued but at a reduced level. While the future of space nuclear power systems is uncertain there are potential space missions which would require space nuclear power systems. The differences between space nuclear power systems and RTG devices are sufficient that safety and facility requirements warrant a review in the context of the unique features of a space nuclear reactor power system.

\section{$1.1 \quad$ PURPOSE}

The purpose of this report is to provide guidelines and considerations in the area of range safety, range facilities, mission safety, and nuclear safety for use by future planners of space missions using a nuclear reactor power system.

\section{$1.2 \quad$ BACKGROUND}

The United States has not launched a nuclear reactor since SNAP 10A in April 1965 although many Radioisotope Thermoelectric Generators (RTGs) have been launched. The number and type of nuclear powered spacecraft, including RTGs, which have been launched and their status is summarized in Table 1.

TABLE 1: SUMMARY OF SPACE NUCLEAR POWER SYSTEMS LAUNCHED BY U.S.

\begin{tabular}{|l|l|l|l|l|}
\hline $\begin{array}{l}\text { Power } \\
\text { Source (a) }\end{array}$ & Spacecraft & Mission Type & Launch Date & Status \\
\hline SNAP-3B7 & Transit 4A & Navigational & 29-Jun-61 & $\begin{array}{l}\text { RTG operated for 15 yr. Satellite now } \\
\text { shut down but operational. }\end{array}$ \\
\hline SNAP-3B8 & Transit 4B & Navigational & 15-Nov-61 & $\begin{array}{l}\text { RTG operated for 9 yr. Satellite } \\
\text { operation was intermittent after 1962 } \\
\text { high-altitude nuclear test. Last reported } \\
\text { signal in 1971. }\end{array}$ \\
\hline SNAP-9A & Transit 5-BN-1 & Navigational & 28-Sep-63 & $\begin{array}{l}\text { RTG operated as planned. Non-RTG } \\
\text { electrical problems on satellite caused } \\
\text { satellite to fail after 9 months. }\end{array}$ \\
\hline
\end{tabular}




\begin{tabular}{|c|c|c|c|c|}
\hline $\begin{array}{l}\text { Power } \\
\text { Source (a) }\end{array}$ & Spacecraft & Mission Type & Launch Date & Status \\
\hline SNAP-9A & Transit 5-BN-2 & Navigational & 5-Dec-63 & $\begin{array}{l}\text { RTG operated for over } 6 \mathrm{yr} \text {. Satellite lost } \\
\text { navigational capability after } 1.5 \mathrm{yr} \text {. }\end{array}$ \\
\hline SNAP-9A & Transit 5-BN-3 & Navigational & 21-Apr-64 & $\begin{array}{l}\text { RTG operated as planned. Mission was } \\
\text { aborted because of launch vehicle } \\
\text { failure. }\end{array}$ \\
\hline $\begin{array}{l}\text { SNAP-10A } \\
\text { (reactor) }\end{array}$ & Snapshot & Experimental & 3-Apr-65 & $\begin{array}{l}\text { Reactor operated successfully as } \\
\text { planned. Satellite shut down reactor after } \\
43 \text { days. }\end{array}$ \\
\hline SNAP-19B2 & Nimbus-B-I & Meteorological & 18-May-68 & $\begin{array}{l}\text { RTGs operated as planned. Mission was } \\
\text { aborted because of range safety destruct, } \\
\text { RTGs recovered. }\end{array}$ \\
\hline SNAP-19B3 & Nimbus III & Meteorological & 14-Apr-69 & $\begin{array}{l}\text { RTGs operated for over } 2.5 \text { yr. (no data } \\
\text { taken after that). }\end{array}$ \\
\hline SNAP-27 & Apollo 12 & Lunar & 14-Nov-69 & $\begin{array}{l}\text { RTG operated for } \sim 8 \text { yr. (until station } \\
\text { was shut down). }\end{array}$ \\
\hline SNAP-27 & Apollo 13 & Lunar & 11-Apr-70 & $\begin{array}{l}\text { Mission abandoned way to moon. Heat } \\
\text { source returned to South Pacific Ocean. }\end{array}$ \\
\hline SNAP-27 & Apollo 14 & Lunar & 31-Jan-71 & $\begin{array}{l}\text { RTG operated for } 6.5 \text { yr. (until station } \\
\text { was shut down). }\end{array}$ \\
\hline SNAP-27 & Apollo 15 & Lunar & 26-Jul-71 & $\begin{array}{l}\text { RTG operated for over } 6 \text { yr. (until station } \\
\text { was shut down). }\end{array}$ \\
\hline SNAP-19 & Pioneer 10 & Planetary & 2-Mar-72 & $\begin{array}{l}\text { RTGs still operating. Spacecraft } \\
\text { successfully operated to Jupiter and is } \\
\text { now beyond orbit of Pluto. }\end{array}$ \\
\hline SNAP-27 & Apollo 16 & Lunar & 16-Apr-72 & $\begin{array}{l}\text { RTG operated for } \sim 5.5 \mathrm{yr} \text {. (until station } \\
\text { was shut down). }\end{array}$ \\
\hline Transit RTG & $\begin{array}{l}\text { "Transit" } \\
\text { (Triad-01 -IX) }\end{array}$ & Navigational & 2-Sep-72 & RTG still operating. \\
\hline SNAP-27 & Apollo 17 & Lunar & 7-Dec-72 & $\begin{array}{l}\text { RTG operated for almost } 5 \text { yr. (until } \\
\text { station was shut down). }\end{array}$ \\
\hline SNAP-19 & Pioneer 11 & Planetary & 5-Apr-73 & $\begin{array}{l}\text { RTGs still operating. Spacecraft success } \\
\text { fully operated to Jupiter, Saturn, and } \\
\text { beyond. }\end{array}$ \\
\hline SNAP- 19 & Viking 1 & Mars & 20-Aug-75 & $\begin{array}{l}\text { RTGs operated for over } 6 \text { yr. (until relay } \\
\text { link was shut down). }\end{array}$ \\
\hline SNAP-19 & Viking 2 & Mars & 9-Sep-75 & $\begin{array}{l}\text { RTGs operated for over } 4 \text { yr. until relay } \\
\text { link was lost }\end{array}$ \\
\hline MHW RTG & LES 8 & Communications & 14-Mar-76 & RTGs still operating. \\
\hline MHW RTG & LES 9 & Communications & 14-Mar-76 & RTGs still operating. \\
\hline MHW RTG & Voyager 2 & Planetary & 20-Aug-77 & $\begin{array}{l}\text { RTGs still operating. Spacecraft } \\
\text { successfully operated to Jupiter, Saturn, } \\
\text { Uranus, Neptune, and beyond. }\end{array}$ \\
\hline MHW RTG & Voyager I & Planetary & 5-Sep-77 & $\begin{array}{l}\text { RTGs still operating. Spacecraft } \\
\text { successfully operated to Jupiter, Saturn, } \\
\text { and beyond. }\end{array}$ \\
\hline GPHS RTG & Galileo & Jupiter & 18-Oct-89 & $\begin{array}{l}\text { RTGs operating. Spacecraft on its way to } \\
\text { Jupiter at the time of this report. }\end{array}$ \\
\hline GPHS RTG & Ulysses & Solar & $6-0 c t-90$ & $\begin{array}{l}\text { RTGs operating Spacecraft in polar orbit } \\
\text { around the Sun at the time of this report. }\end{array}$ \\
\hline
\end{tabular}


a) SNAP stands for Systems for Nuclear Auxiliary Power. All odd-numbered SNAP power plants use radioisotope fuel. Even-numbered SNAP power plants have nuclear fission reactors as a source of heat. MHW RTG stands for the multihundred-watt radioisotope thermoelectric generator.

SOURCE: Nuclear Safety, Volume 32, Number 1, January - March 1991

1.3

SCOPE

This report addresses safety guidelines for space nuclear reactor power missions in the areas of range safety, range facilities, mission safety, and nuclear safety. Safety considerations include DoD and non-DoD (e.g. NASA) missions. The space nuclear reactors which are germane to this report are nuclear power, nuclear propulsion, and $\mathrm{Bi}$-Modal types of reactors. This report will not address test or certification of the nuclear reactor nor will it address operation of the nuclear reactor prior to delivery to the launch site and integration with the spacecraft and launch vehicle. This report will not address RTGs except for supporting information relating to nuclear safety.

The radiation safety guidelines for space nuclear power systems are numerous, voluminous, very detailed, and updated periodically. As a consequence the guidelines or suggestions made in this report are general. However the appendix contains a lengthy list of references which can serve as a starting point to obtain the current detailed information.

Major milestones are identified as a planing aid for range safety, mission safety, and nuclear safety, and environmental impact. These milestones are general in nature since they can be program dependent and also regulations are subject to change.

\section{$\mathbf{2 . 0}$}

NUCLEAR SPACE SAFETY GUIDELINES AND CONSIDERATIONS

The following sections present guidelines and rationale for conducting space nuclear reactor operations in four areas: Coordination, Range Safety (including facilities), Mission Safety, and Nuclear Safety.

\section{$2.1 \quad$ COORDINATION}

One of the safety concerns is the need to coordinate safety issues and work among: range safety, nuclear safety, and mission safety so that there is a coherent and integrated approach to safety. Range safety for DoD and non-DoD missions focuses on the range requirements that have to be met before launch approval is given by the range commander. Mission safety focuses on the safety requirements that have to be met regarding launch trajectory and orbit parameters including spacecraft operations regarding propulsive maneuvers. Nuclear safety focuses on functional requirements for reactor startup, inadvertent criticality, radiological release during routine operation, disposal, inadvertent reentry, and safeguards. There is clearly some overlap among these areas that must be coordinated to avoid unnecessary duplication of effort and to ensure all safety issues are adequately covered.

One of the previous nuclear space reactor programs defined an integrated program safety plan whose purpose was to provide a document which served to coordinate the various safety activities in Mission Safety, Range Safety, and Nuclear Safety. The integrated program safety plan defined, from a safety perspective, the relationships between the various organizations to design, construct, test, integrate, launch, and control the nuclear reactor and spacecraft. The plan also established a safety working group which was intended to coordinate activities between Mission Safety, Range Safety, and Nuclear Safety. The plan also provided top level guidance to the various organizations on the system safety tasks, activities and documentation. A generic safety organization chart, based 
on experience from a previous nuclear space reactor program, is presented as an example in Figure 1.

\section{FIGURE 1: EXAMPLE SAFETY ORGANIZATION}

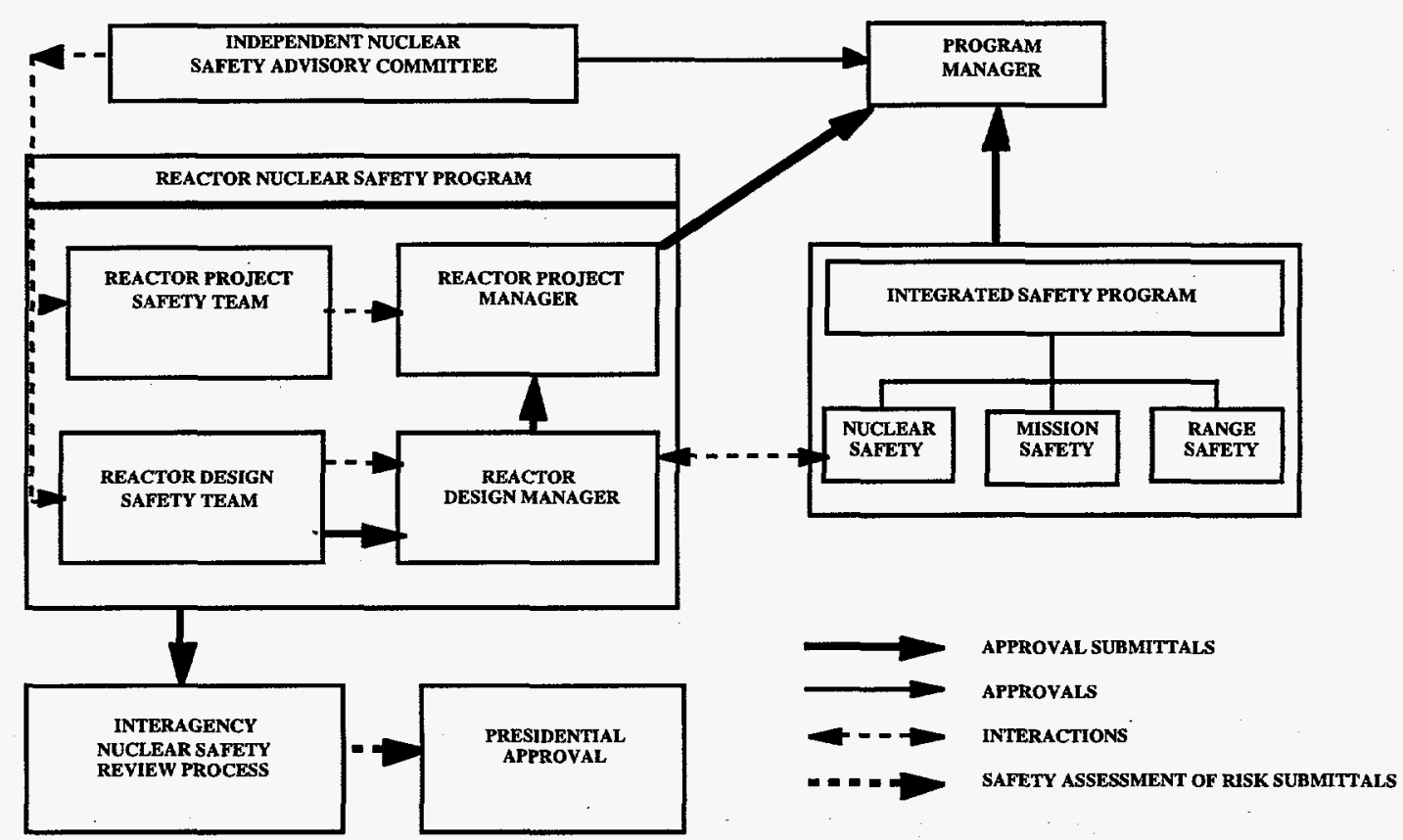

The specific objectives of the Integrated Program Safety Plan were:

1. Establish a safety working group composed of members from the Mission Safety, Range Safety, and Nuclear Safety activities including representatives from the range and the launch vehicle contractor.

2. Coordinate safety issues among: range safety, nuclear safety, and mission safety, so that the program manager obtains coherent and integrated safety information in response to questions or concerns.

3. Assist in the design process so that the spacecraft design takes a systems approach, including reliability and quality control, to safety requirements.

4. Foster safety consciousness among all program participants and throughout all aspects of the program.

5. Review the test programs of the reactor and spacecraft bus, and the integrated spacecraft to ensure that the plans will provide for a safely conducted test program and ensure that tests are conducted to verify accordance with the appropriate regulations.

6. Develop a radiological control and contingency plan to ensure that the spacecraft processing at the launch site is performed in accordance with appropriate regulations from delivery of the first hardware segment to the launch site and continuing until the spacecraft has achieved sufficiently high orbit. 
Although every program has a different mission and objective and is comprised of different organizations consideration of an integrated program safety plan would be worthwhile for any future space nuclear reactor programs.

\section{2}

\section{RANGE SAFETY}

A second safety area is concerned with the range safety requirements. These range safety requirements are covered (or referenced to other documents) in a document such as "Eastern and Western Range Requirement (EWR) 127-1". This is the controlling safety document for launch from the Eastern and Western Ranges (i.e. Cape Canaveral and Vandenberg) and specifies the range safety requirements. This document is also shared by Vandenberg Air Force Base but there are differences in requirements for range safety at the Eastern Range and the Western Range. Variations are caused by geographical differences that change risk levels for launch operations, organizational variations, and different user requirements. The EWR 127-1 is the document which defines the hardware and operational safety requirements applicable to the entire launch vehicle including the spacecraft and a nuclear reactor. The process of meeting the standards specified in EWR 127-1 begins at the inception of the program design activity. The EWR 127-1 provides minimum design standards and margin criteria that must be designed into the hardware and test specifications to verify these designs. The EWR $127-1$ is tailored for each program to accommodate, within safety restrictions, unique program characteristics. To assure the safety of the launch site and the general public, the range safety responsibility includes all the pre-launch activity and extends through the launch phase up to spacecraft orbit insertion.

One of the significant considerations is that the space nuclear reactor must comply with the safety design criteria and operational requirements in EWR-127-1 in assuring the safety during spacecraft processing and through the launch phase. This means that the interfaces between the space nuclear reactor and the spacecraft bus will be designed to the EWR-127-1 guidelines recognizing that these requirements focus primarily on the hazards associated with RTGs and ionizing radiation sources, such as those used for calibration of instruments. These requirements need to be examined in context of a space nuclear reactor and guidelines proposed so that additional costs and design constraints are not imposed unnecessarily and so that unique safety requirements for nuclear space reactors are addressed. As an example, interlocks and latching relays may be required to prevent inadvertent criticality of the reactor during pre-launch testing. Such a requirement can have an impact on the design process of the space nuclear reactor power system, integration of the reactor with the spacecraft/launch vehicle, and pre-launch testing. Another example is development of a radiological control and contingency plan by the range's Radiological Protection Officer to ensure that the spacecraft processing at the launch site is performed in accordance with appropriate regulations from delivery of the first hardware segment to the launch site and continuing until the spacecraft has achieved sufficiently high orbit. Some of these requirements, based on RTGs, include extensive radiological reaction teams and monitoring aircraft. These requirements might be reduced due to the significantly lower level of radioactivity of a nuclear reactor as opposed to a RTG.

Early coordination between the launch vehicle contractor, range safety officers, and safety representatives from the space nuclear reactor program is recommended to identify potential safety concerns early in the program and to minimize any cost or schedule impact. Continuation of this line of communication throughout the program and through launch operations is essential to assure proper scheduling of events and activities while the space nuclear reactor and spacecraft is being readied for launch.

There are a few key considerations and documents which apply to safe launch of all spacecraft regardless of whether they are carrying nuclear material or not. Because they can impact the planning for launch of space nuclear reactors they are mentioned briefly. 
One of the principal documents is the Missile System Pre-launch Safety Package (MSPSP). Typically this is prepared by the launch vehicle contractor. Experience from a previous nuclear space reactor program indicated a preference by the range for a complete MSPSP which addressed the launch vehicle, the spacecraft, and the nuclear space reactor. The MSPSP describes in detail hazardous subsystems of the vehicle/payload design to include:

$\begin{array}{ll}\text { - } & \text { Propulsion } \\ \text { - } & \text { Elessurization } \\ \text { - } & \text { Ordnancal } \\ \text { - } & \text { Radiation Sources } \\ \text { Hazardous materials }\end{array}$

Early coordination between the launch vehicle contractor, range safety officers, and safety representatives from the space nuclear reactor program is recommended so that agreements can be made regarding: what information is supplied, by whom, and who incorporates it into the MSPSP. Another significant document is the Flight Analysis Data Package (FADP) which provides detailed information on the launch vehicle performance and trajectory/orbit data. Regarding radiation safety early contact is recommended with the Radiation Protection Officer at either the Eastern or Western Ranges, or Kennedy Space Center for non-DoD programs.

In addition to these documents and considerations special requests must be planned for and made for any services required of range assets (e.g. ships, aircraft) to support the mission. Given concern with radiation hazard and Special Nuclear Material these requests may be significant.

The range requirements for which some specific guidelines or rationale is given for a space nuclear reactor power system presented in the following sub-sections.

\subsubsection{TRANSPORTATION AND HANDLING OF NUCLEAR FUEL}

An approach which has merit is to deliver the nuclear reactor fuel elements by certified government carrier to the launch site in approved containers and stored in an approved storage facility with appropriate security. The reactor will be verified to be in a safe configuration and be fueled by qualified technicians using approved procedures. This approach can reduce logistics complexity and cost of a special shipping cask for shipping a fueled reactor. However reactor design may preclude this option if the fuel elements are not readily removable.

\subsubsection{GROUND TESTS AT LAUNCH SITE}

There are two basic approaches which can be taken regarding processing the reactor at the launch site. One of these is not do Zero Power Testing of the nuclear reactor at the launch site. Performing a Zero Power Test may require such things as: additional monitoring equipment, additional monitoring crews, location of the reactor in a low populated and remote site on the range, evacuation of personnel from the area, additional requirements of security of the building, and additional requirements on the building to run at negative pressure. During integration, test, and pre-launch preparations at the range the safety monitoring and control of the nuclear reactor and spacecraft would be conducted in accordance with EWR 127-1. Major radiological source support supplied by the Eastern Range will be defined in the Ionization Radiation Protection Program prepared by 45th SPW and AFR 100-1 (HOT SHOT), and for non-DoD programs the KSC documents (KHB 1860.B and KHB 1860.1A appendix D2) apply. All hazardous test procedures would have to be submitted for approval as required. 
The other approach is to assume fueling at the launch site and more than a zero power test. This is a conservative assumption to preclude a situation where there might be "last minute" design changes which could result in facing an insurmountable engineering problem or run into a difficult safety issue.

A possible method for processing the reactor at the launch site with no Zero Power Testing is as follows:

1. Criticality tests would be done previously at a U.S. Critical Facility (e.g. Los Alamos) and the core load would be tagged. The core would be unloaded.

a. The core would be re-loaded into the tagged locations but the load for the anti-criticality device would not be loaded into the core.

b. 1/M would be monitored.

c. Verify worth of anti-criticality device, if used.

d. Unload core and verify tagging of fuel load and location.

2. The fuel would be transported to the storage facility at the launch site.

3. Fuel would be loaded into the core in the exact tagged order and location without loading the anti-criticality fuel load.

4. 1/M data would be collected and compared with 1/M collected at the U.S. Critical Facility:

5. Prior to mating with the spacecraft and launch vehicle the anti-criticality device, if used, would be loaded and installed.

6. Lock-outs on the anti-criticality device, if used, would prevent inadvertent criticality until sufficiently high orbit is achieved and commands for going critical are sent to the spacecraft from the ground.

\subsubsection{LAUNCH PAD AND EXPLOSION ACCIDENTS}

One of the concerns which has to be addressed as part of the INSRP process is launch pad and explosion accidents. One of the obvious issues is the case of the launch vehicle exploding on the launch pad and the reactor core is ruptured causing nuclear material to be released. Since the reactor has never been operated at high power the level of radioactivity will be low. However other cases which may be of more concern is the event in which the reactor vessel lands in the water cooling basin near the launch pad or another event in which the launch vehicle ruptures and liquid propellant (e.g. liquid hydrogen) escapes and pools around the reactor. In both of these accidents the additional moderation can increase core reactivity and measures must be taken to reduce or eliminate this event. Other scenarios, such as immersion in wet sand, or fuel ejection will need to be considered as well.

\subsection{4}

\section{CONTINGENCY PLANS}

As part of the range operations a contingency plan is developed which provides requirements and plans for operations including communications, search, and recovery in the event of unintentional release of radioactive materials. Such a plan, HOT SHOT, was developed by the Eastern Space and Missile Center (Patrick Air Force Base) for the Galileo and Ulysses programs. The equivalent plan for non-DoD at KSC would be KHB 1860.1A appendix D2.

An important distinction needs to be made in that the contingency plans have previously addressed RTGs where the toxicity and radioactivity is much higher than for space nuclear reactors (assuming that they have not yet gone critical before launch). This contingency planning for launch of a space nuclear reactor needs to account for this difference which can affect the level of radiation monitoring equipment and teams and surveillance aircraft required. One of the requirements noted for RTGs is the use of an underwater acoustic beacon for assistance in recovery of the radioactive material. A 
similar requirement would probably be appropriate for a space nuclear reactor but more from the point of view of recovery of weapons grade nuclear material rather than because of radioactivity or toxicity risks.

\subsection{5 \\ SAFEGUARDS FOR NUCLEAR MATERIAL}

One of the previous nuclear space reactor programs did use sufficient quantity of highly enriched uranium such that there was concern with safeguarding this material (reference 1) since it was of weapons grade quality. A point to consider in the future is the attempt at non-proliferation which would reduce the quality of the special nuclear material for the space nuclear reactor so that it would not be weapons grade material. A study was conducted on the use of low or medium enriched uranium in space nuclear power systems (reference 6) which indicated that this approach may result in unfavorable reduction in launch vehicle payload margin due to the increase in fuel mass required for criticality.

\subsubsection{HAZARDOUS MATERIALS}

There are some hazardous materials associated with a space nuclear reactor which are identified below.

1. PYROTECHNIC DEVICES

The nuclear reactor and the spacecraft each will contain some number of pyrotechnic devices which will be used to cut bolts, deploy antenna booms, release thermal shields, etc. Generally these devices will be standard flight proven devices and will conform to prescribed safety standards.

2. LIQUID METAL COOLANT

The typical space nuclear reactor coolant system will include liquid-metal coolant, such as sodium-potassium ( $\mathrm{NaK}$ ), which is flammable when brought into contact with water. Specifications will have to be provided to the range for any special facilities required to process, contain, or dispose of the liquid-metal coolant in the event of a leak. Standard firefighting methods such as water dousing systems already in place are forbidden when dealing with liquid metal fires.

3. MODERATOR MATERIALS

The typical nuclear reactor may contain toxic substances for moderator materials such as Beryllium (Be) and Zirconium Hydride $\left(\mathrm{ZrH}_{1.85}\right)$. Information would have to be provided to the range concerning personnel risk to this material.

4. RADIATION SHIELD MATERIAL

Lithium-hydride $(\mathrm{LiH})$ is frequently proposed for use as a radiation shield to attenuate the neutron and gamma radiation. Information would have to be provided to the range concerning personnel risk to this material.

5. PROPELLANT

The typical Bi-Modal nuclear reactor may have tanks containing gases such as ammonia or hydrogen which is used as a propellant . Specifications concerning the safety factor of the pressure tanks, handling procedures for the gas, and information concerning personnel risk to this material need to be provided to the range.

\section{BATTERY CHEMISTRY}

The typical nuclear reactor may contain batteries. Information would have to be provided to the range concerning personnel risk from these batteries. 


\section{SPECIAL NUCLEAR MATERIAL (SNM)}

A nuclear reactor will contain a significant quantity of highly enriched uranium. A nuclear safety assessment of the nuclear reactor needs to be performed and the information provided to the range concerning personnel risk and procedures for proper handling of this material

\section{IONIZING RADIATION SOURCES}

The spacecraft may contain small amounts of radioisotopes which are to be used as reference radiation in spacecraft sensors. Information would have to be provided to the range concerning personnel risk to this material.

9. NON-IONIZING RADIATION

The spacecraft will have a variety of radio frequency emitters. Information would have to be provided to the range concerning personnel risk to this equipment.

10. TOXIC GASES

A nuclear reactor generating electric power by use of thermionic elements may use a gas such as cesium vapor (Cs) in the thermionic fuel element interelectrode gap. The information concerning personnel risk and procedures for proper handling of this material need to be provided to the range.

\section{PRESSURE VESSELS}

A nuclear reactor generating electric power for electric propulsion may use a gas such as Xenon gas under pressure. Steps must be taken to ensure that the pressure vessel meets the requirements specified in the appropriate safety documents, such as EWR 127-1.

One of the significant concerns of processing a nuclear space reactor is the production of mixed waste. Every effort should be made to prevent, in the event of an accident, generation of waste material composed of a mix of toxic, radiological, flammable, and biological materials.

\subsection{7}

FACILITY GUIDELINES

Part of the range safety requirements are the facility requirements. There is a need to address those facility requirements that are unique to processing and testing a space nuclear reactor power system at a range. As an example a RTG requires a building with a negative pressure differential to prevent plutonium particles escaping to the open environment. However this requirement may be reduced or eliminated due to the significantly lower level of radioactivity and toxicity of a nuclear reactor as opposed to a RTG. There is another unique aspect of a space nuclear reactor power system at a range that associates with safeguarding of special nuclear material. This may impose a set of safeguard requirements resulting in modifications to existing structures and increase in personnel to provide a protective force.

This section addresses the guidelines which might be followed by a space nuclear reactor power program at the range in order to receive, process, and launch the spacecraft and nuclear reactor. The term facility is used in a broad context and covers the following three areas:

Launch Site: focuses on the geographical area/location

Range: focuses on operational related areas such as radar, telemetry, monitoring aircraft 
Facility: includes buildings, fire equipment, cranes communications, fencing, shielding, radiation monitors, and parking. (safeguard of Special Nuclear Material (SNM) would be included in this area)

For each of the above areas there are requirements imposed by: DOE, DoD, Mission, Spacecraft, nuclear reactor, Environmental, Government (Federal/State/Local), and the Range Commander.

There are several considerations which are germane to the guidelines proposed in the following sections. These considerations are:

- Performing a Zero Power Test may necessitate such things as: additional monitoring equipment, additional monitoring crews, location of the reactor in a low populated/remote site on the range, evacuation of personnel from the area, additional security of the building, and possibly using a building which can be operated at negative air pressure. As a consequence it is very desirable not to perform zero power testing. Note that at the time of preparation of this document there were preliminary plans for a primary storage cask which could alleviate the need for a negative pressure differential.

- Activity of the fuel load for the flight nuclear reactor is low (e.g. less than 3 curies)

- The nuclear reactor fuel of highly enriched uranium is classified as Category I fuel with attractiveness Category B (reference 1).

\subsubsection{1}

\section{LAUNCH SITE}

The launch recommendations based on experience with a previous nuclear space reactor program, for launch of a space nuclear reactor proposed for consideration:

1. Launch into sufficiently high orbit such that the fission product inventory has had time to decay to the level of the actinides prior to reentry. NOTE this is mission dependent such that the mission objectives may require low earth orbits or an earth swing-by.

2. Make maximum use of existing facilities which can support processing of nuclear material including contingency operations to hold down program cost.

3. Launch site location should be able to support short term (e.g. 48 hours) mission control center operations including telemetry uplink/downlink and processing of spacecraft tracking data from worldwide tracking and communications networks. This is to insure continuous monitoring of status of the nuclear space reactor during orbit insertion.

4. Minimize flight over inhabited areas during boost phase to reduce risk in the event of launch abort. 


\subsubsection{RANGE}

The range recommendations proposed for launch of a space nuclear reactor are:

1. Once launched the USSPACECOM will maintain track of the spacecraft.

2. The range/KSC shall develop a Radiation Protection Plan/Emergency Preparedness Plan (reference 2). The Mission Integrator will provide information as needed to the range for completion of the plan.

3. Program and support personnel (e.g. security personnel) working around the fuel or the fueled reactor will be trained, by the range, as to the hazards created by radioactive substances (reference 3,19 ).

4. Fire Protection Personnel will be trained, by the range, to respond to metallic fires (e.g. $\mathrm{NaK}$ ).

5. Personnel working in the facility with the fuel and/or fueled space nuclear reactor will be equipped with dosimeters and/or monitoring badges and exposure records will be maintained by the range (reference 3,19 ).

6. A Radiation Control Center (RADCC) will be established and will be manned during launch. As a minimum manning will consist of the Radiation Protection Officer, Lead Federal Agent (the agency which owns and operates the payload which includes the reactor), and contractor health physics personnel (reference 4,18).

7. Adequate number of properly instrumented field radiation monitoring teams will be on standby with adequate transportation during nuclear fuel handling and launch. (reference 4,18 ).

8. Decontamination teams and assets will be available during nuclear fuel handling and launch.

9. Radiation surveys will be conducted on the space nuclear reactor prior to its arrival at the launch site (reference 5).

\subsubsection{FACILITIES}

There are no specific requirements defined for facilities for space nuclear reactors. All requirements are currently based on RTGs. One of the areas which would have to be reviewed as part of a nuclear space reactor program is the facility requirement. However based on experience with a previous nuclear reactor program some of the guidelines and issues which were considered were as follows:

1. The Directorate of Nuclear Surety (AFSA/SEN) shall conduct a nuclear safety survey of the range to evaluate the adequacy of range safety procedures, contingency plans, and safety hardware (reference 1).

2. Radiation exposure (see following table) will be monitored in and around the facility where the fuel or the fueled space nuclear reactor is located (reference 3). 
- Portable radiation instruments capable of measuring alpha, gamma, and neutron radiation will be provided (reference 2 ).

- The facility with the space nuclear reactor shall be equipped with constant air monitoring instrumentation with an audible alarm (reference 2).

- The radiation detection instrumentation shall be routinely serviced and calibrated and records maintained of the servicing and calibration (reference 2 ).

\section{TABLE 2: $\quad$ REACTOR RE-ENTRY ISSUES MATRIX}

Occupational Radiation Worker Radiation Exposure Limits

\begin{tabular}{|llll|}
\hline $\begin{array}{l}\text { Exposure } \\
\text { Period }\end{array}$ & $\begin{array}{l}\text { Whole Body, Critical } \\
\text { Body Organs }\end{array}$ & $\begin{array}{l}\text { Lens of } \\
\text { Eye }\end{array}$ & $\begin{array}{l}\text { Skin or to each of } \\
\text { the extremities }\end{array}$ \\
\hline Weekly & $100 \mathrm{mrem}(1 \mathrm{mSv})$ & $\begin{array}{l}300 \mathrm{mrem}(3 \\
\mathrm{mSv})\end{array}$ & $1000 \mathrm{mrem}(10 \mathrm{mSv})$ \\
Quarterly & $1250 \mathrm{mrem}(12.5 \mathrm{mSv})$ & $\begin{array}{l}3700 \mathrm{mrem}(37 \\
\mathrm{mSv})\end{array}$ & $12500 \mathrm{mrem}(125 \mathrm{mSv})$ \\
Yearly & $5000 \mathrm{mrem}(50 \mathrm{mSv})$ & $\begin{array}{l}15000 \mathrm{mrem}(150 \\
\mathrm{mSv})\end{array}$ & $50000 \mathrm{mrem}(500 \mathrm{mSv})$ \\
\hline
\end{tabular}

From: Title 10 Code of Federal Regulations 20.1201

* Approval to exceed limits must be obtained from the 45th Space Wing Radiation Protection Officer. Requests for such approval shall include explanation of requirements and adequate justification.

3. The requirement for using a facility with capability of maintaining negative pressure has not been resolved. This requirement derives from RTGs but since the radioactivity level of a nuclear space reactor can be substantially lower than an RTG and the toxicity of the particulates is substantially less that that of an RTG the need for maintaining negative air pressure is not definitive. Proposed guidance is to use a facility which is capable of maintaining operational areas at a negative differential air pressure of at least 0.25 inches of water relative to adjacent rooms or areas. The facility should have the capability of having 5 to 7 air changes per hour and have the exhaust equipped with High Efficiency Particulate Air (HEPA) filters. The exhaust shall be monitored for radiation levels (reference 2). The facility should have continuous radiation monitoring to determine if the reactor is leaking or if the radiation level is changing.

4. Storage and fuel handling and movement in the facility with the space nuclear reactor shall ensure that critical mass cannot be attained (reference 2).

5. Any construction or modification to the facility with the space nuclear reactor shall be approved by the Radiation Protection Committee (reference 3).

6. All radiation areas will be identified, posted, and controlled in accordance with 45th SPW or KSC regulations (reference 3, 19). 
7. Shielding requirements in and around the facility with the fuel and/or fueled space nuclear reactor may be required depending on measured/predicted radiation levels for the space nuclear reactor. Shielding requirements will also be applied, as required, to radioactive calibration sources (reference 3 ).

8. Fire suppression systems that use water will be disabled in facilities with the space nuclear reactor due to use of liquid metal coolant (e.g. NaK).

\subsubsection{SAFEGUARDS}

1. The facilities must be granted approval to receive, process, or store Special Nuclear Material in accordance with DOE regulations (reference 6).

2. The facilities will be guarded by protective force personnel (reference 1).

3. Containers of SNM that are shipped or transported shall be sealed with tamper-indicating devices (reference 1).

4. The access to the facility with the space nuclear reactor and fuel will be equipped with locks and protective force personnel to ensure that a single individual cannot gain access to the facility (reference 1).

- Access control procedures to the facility with the space nuclear reactor and fuel will be such that only authorized individuals are permitted to open doors to the secure area and that at least two authorized persons are required to obtain entry ("two-man" rule) and that positive identification and verification is performed (reference 1).

- The facility with the space nuclear reactor shall be equipped with a DOE approved intrusion alarm system (reference 1).

5. Transportation of SNM shall be with escort by protective force personnel (reference $1,7,8$ ).

- Personnel assigned to the DOE convoy may be identified by their DOE Form AL-150, by serially numbered metal shields designating the individual as a US DOE Federal Officer, a DOE Form F5631.19, DOE Employee Identification Badge, a SF 46, a US Government Motor Vehicle Operator's Identification Card, and civilian driver's license.

- On arrival at the entrance to the area in which loading or unloading will take place the DOE convoy commander certifies that all convoy vehicles have been cleared of unauthorized personnel and kept under continuous observation following sanitation. The DOE convoy commander must maintain custody and security of the shipment until custody is transferred to the Air Force or other agency depending on the mission.

- Security Manning requirements

- Area Supervisor

- SAB Complex Entry Controller

- SAB High Bay close in Sentry / entry Controller 
- SAB High Bay close in Sentry

- Close Boundary Sentry - four

- Alarm Response Team Leader - two

- Alarm Response Team Member - two

- Security Response Team Leader

- Security Response Team Member

- Fire Team Leader

- Fire Team Member - three

A third safety area is associated with the mission planning. Guidelines or requirements need to be defined for operation of the space nuclear reactor power system once it has been launched. An example is the requirement or guideline for a sufficiently high orbit which reduces radiological risk to the earth environment. Some thought must be given as to whether this should be a requirement or a guideline. If it is a requirement then some missions may be precluded if they need to be closer to earth in order to meet the mission objectives. Areas in mission planning for which some specific guidelines or rationale is given for operation of a space nuclear reactor power system are presented in the following sub-sections.

\subsubsection{TRAJECTORY AND ORBIT PARAMETERS}

During launch extensive tracking of the launch vehicle/payload is necessary so if there is an abort the impact point of the reactor can be determined. This probably requires assets beyond what is available locally at the range. Also extensive radar tracking coverage is desired to verify that orbit insertion and orbit stability have been achieved. In addition to radar tracking extensive telemetry is desirable to monitor separation of the spacecraft, with its nuclear reactor, from the launch vehicle. Extensive telemetry coverage is also desirable to monitor reactor startup sequence.

\subsection{2 \\ INADVERTENT CRITICALITY}

One of the major safety concerns is inadvertent criticality. The guideline is to have a reactor design which precludes inadvertent criticality particularly at the launch site during spacecraft mating, prelaunch testing, or as a result of launch accidents. In a previous nuclear space reactor program a decision was made to modify the reactor to allow for an anti-criticality device which would insert the final fuel load after stable orbit had been reached. The significant feature of the anti-criticality device is that once a sufficiently high orbit is achieved then the command would be sent to the spacecraft which: (a) causes the anti-criticality device to insert the remainder of the fuel into the core and then (b) initiate reactor start-up and to go critical. The sufficiently high orbit is one in which the orbit lifetime is sufficiently long enough that the radioactive inventory decays down to the level of the actinides. For a circular orbit of at least 1000 kilometers the orbit would be stable for beyond the approximately 700 years required for the radioactive decay of nuclear reactor fuel (e.g. 27 kilograms of Uranium Dioxide enriched $96 \%$ with $U_{235}$ ) to reach the level of the actinides. Figure 2 illustrates the approximate relationship between orbit altitude and orbit life-time. Note that there are many factors to consider in computing orbit lifetime such as solar wind and lunar and solar gravitational effects. Figure 3 illustrates the approximate level of radioactivity over time for a reactor which has been operated for approximately two years before shutting down. These two figures are used primarily to illustrate the approach to determine sufficiently high orbit. However the mission of the program using a space nuclear reactor may require a low-earth orbit. As a consequence levying a blanket requirement for all nuclear space programs to have sufficiently high orbits may preclude some necessary missions from being flown. 


\section{FIGURE 2: APPROXIMATE ORBIT LIFETIME AS A FUNCTION OF ALTITUDE}

Source: NEP Space Test Program Preliminary Nuclear Safety Assessment (Second Draft); U.S. Topaz II Flight Safety Team; P.O.C. Albert C. Marshall; 10/1/92

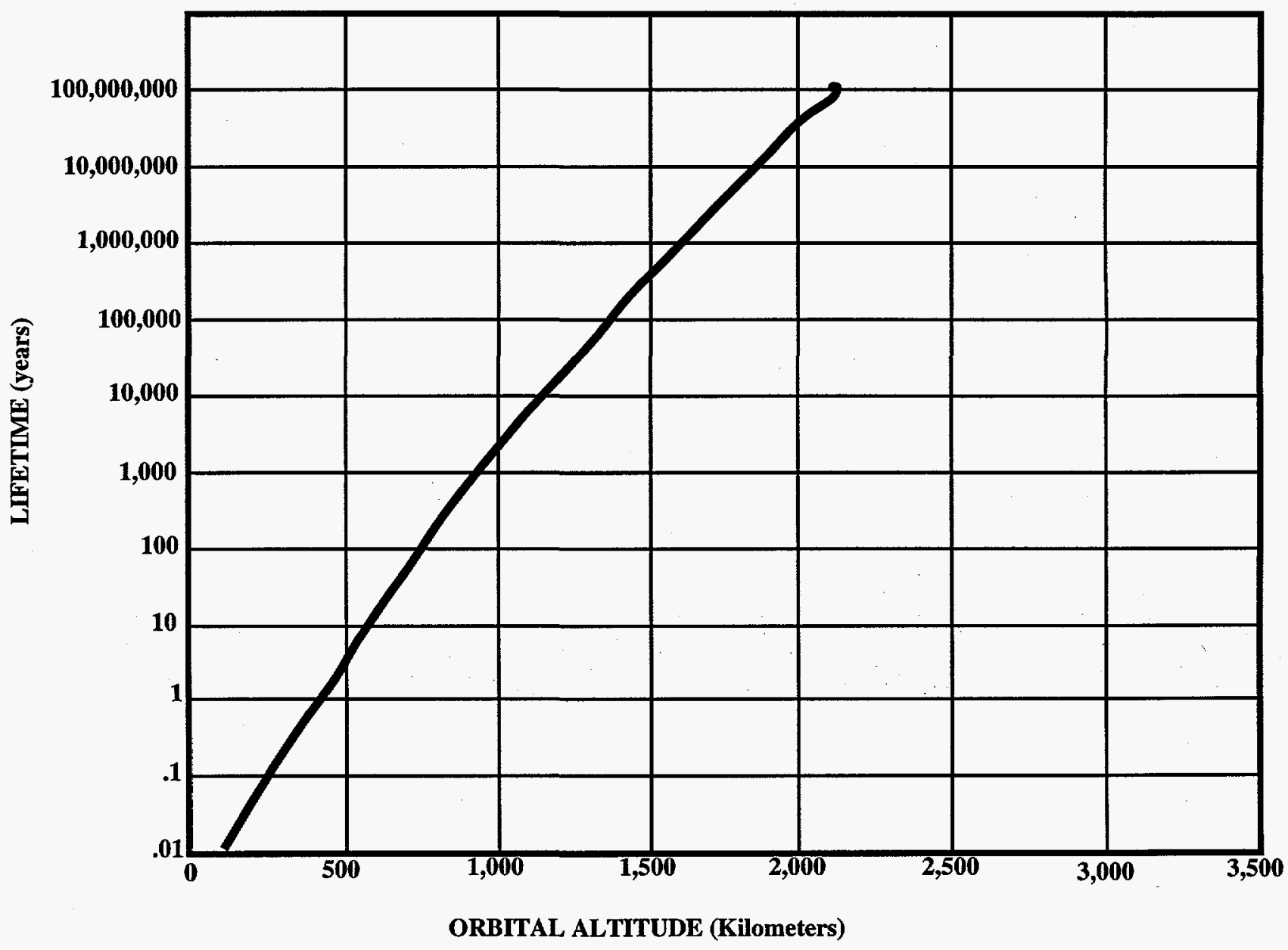




\section{FIGURE 3: APPROXIMATE RADIOACTIVE DECAY AS A FUNCTION OF TIME}

Source: NEP Space Test Program Preliminary Nuclear Safety Assessment (Second

Draft); U.S. Topaz II Flight Safety Team; P.O.C. Albert C. Marshall; 10/1/92

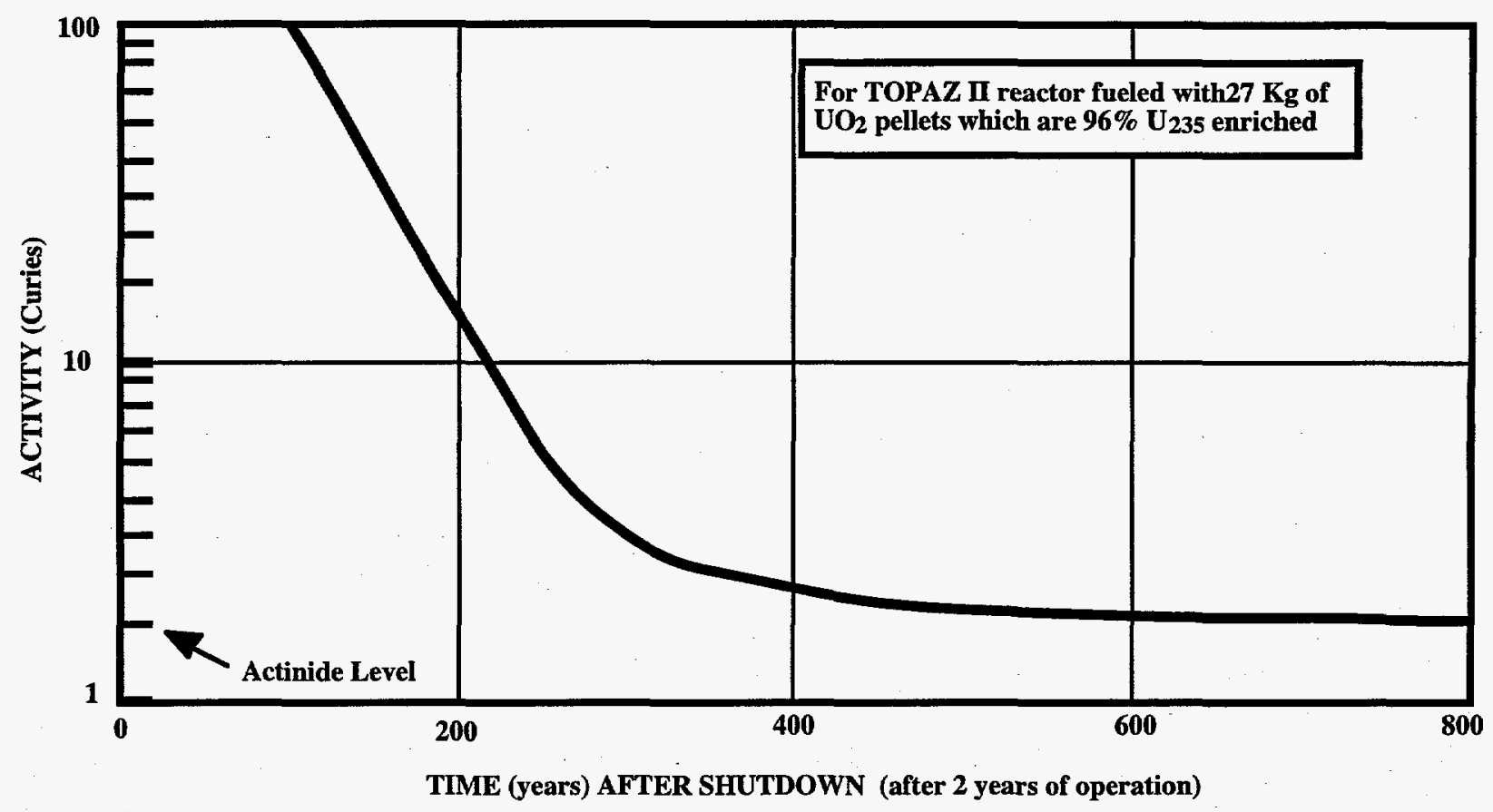

\subsubsection{RADIOLOGICAL RELEASE TO THE SPACE ENVIRONMENT}

One of the areas which needs to be addressed is the event of a radiological release to the space environment. Part of this issue is related to U.S. space policy which is intended to minimize space debris. Another part of this issue associates with radiological release and subsequent re-entry into the earth's bio-sphere. However the mission requirements may dictate a lower orbit in which case the possibility of re-entry will be an issue.

\subsection{4}

REACTOR SHUT-DOWN / ON-ORBIT DISPOSAL

Any nuclear space program should have some plan for shut-down of the space nuclear reactor at the end of the useful life of the reactor. The result would be a reactor which had nuclear material with residual activity that would eventually decay to the level of the actinides. 
In addressing re-entry of the reactor a matrix of options is presented.

\section{TABLE 3: $\quad$ REACTOR RE-ENTRY ISSUES MATRIX}

\begin{tabular}{|c|c|c|c|}
\hline $\begin{array}{c}\text { REACTOR } \\
\text { CONDITION }\end{array}$ & EVENT & SAFETY ISSUE & CONSIDERATIONS \\
\hline COLD REACTOR & LAUNCH ABORT & $\begin{array}{l}\text { WATER IMMERSION OR } \\
\text { OTHER SCENARIOS } \\
\text { WHICH COULD CAUSE } \\
\text { CORE TO GO CRITICAL }\end{array}$ & $\begin{array}{l}\text { DESIRABLE TO DESIGN } \\
\text { CORE OR USE ANTI- } \\
\text { CRITICALITY DEVICE } \\
\text { TO } \\
\text { REDUCE/ELIMINATE } \\
\text { RISK }\end{array}$ \\
\hline COLD REACTOR & $\begin{array}{l}\text { LAUNCH ABORT WITH } \\
\text { RE-ENTRY }\end{array}$ & $\begin{array}{l}\text { DISPERSAL OF } \\
\text { RADIOACTIVE } \\
\text { MATERIAL AND TOXIC } \\
\text { MATERIALS }\end{array}$ & $\begin{array}{l}\text { ANALYSIS TO } \\
\text { DETERMINE } \\
\text { CONDITIONS FOR } \\
\text { INTACT OR BREAKUP } \\
\text { OF REACTOR CORE. } \\
\text { THIS WOULD } \\
\text { DETERMINE NEED FOR } \\
\text { RE-ENTRY SHIELD }\end{array}$ \\
\hline COLD REACTOR & LAUNCH ABORT & $\begin{array}{l}\text { ACCOUNTABILITY OF } \\
\text { SNM }\end{array}$ & $\begin{array}{l}\text { NEED TRACKING FOR } \\
\text { IMPACT } \\
\text { DETERMINATION AND } \\
\text { CONTINGENCY PLANS } \\
\text { FOR RETRIEVAL. USE } \\
\text { OF LOWER GRADE } \\
\text { FUEL MAY REDUCE } \\
\text { RISK. }\end{array}$ \\
\hline COLD REACTOR & $\begin{array}{l}\text { RE-ENTRY AFTER } \\
\text { ORBITAL INSERTION }\end{array}$ & $\begin{array}{l}\text { DISPERSAL OF } \\
\text { RADIOACTIVE } \\
\text { MATERIAL AND } \\
\text { TOXIC MATERIALS }\end{array}$ & $\begin{array}{ll}\text { - } & \text { RADIOACTIVITY } \\
\text { OF MATERIAL IS } \\
\text { LOW. } \\
\text { - } \\
\text { SELECTION OF } \\
\text { ORBIT WILL } \\
\text { AFFECT } \\
\text { PROBABILITY OF } \\
\text { RE-ENTRY } \\
\end{array}$ \\
\hline HOT REACTOR & RE-ENTRY & $\begin{array}{l}\text { DISPERSAL OF } \\
\text { RADIOACTIVE } \\
\text { MATERIAL AND } \\
\text { TOXIC MATERIALS }\end{array}$ & $\begin{array}{l}\text { SELECTION OF ORBIT } \\
\text { WILL AFFECT } \\
\text { PROBABILITY OF RE- } \\
\text { ENTRY }\end{array}$ \\
\hline
\end{tabular}


One issue which arose with one of the previous nuclear space reactor programs was interference with other satellite operations. Emission of gamma rays, for example, as a result of reactor operation could interfere with scientific instruments on other satellites. Analysis needs to be done on a case by case basis to determine what satellites could be affected, for how long a period (since it is orbit dependent), and the extent of the interference. There is currently no single agency with responsibility for this issue.

Another aspect of the interference issue is space debris. The reactor or spacecraft may eject covers, battery electrolyte, or liquid metal coolant. General space policy is to minimize generation of space debris.

\subsubsection{ORBITAL SAFETY}

The necessary orbital safety documentation required to resolve orbital safety issues is generally developed in accordance with the USSPACECOM and the Consolidated Space Test Center (CSTC) requirements or NASA depending on whether the mission is DoD or non-DoD. Note that at the time of this report CSTC was in the process of being renamed and the relationship with other Air Force organizations was being addressed. Technical support will be provided as required. Orbit parameters required for a sufficiently high orbit need to be developed and the launch vehicle contractor provides the launch vehicle flight plan necessary to achieve this objective. The United States Space Command (USSPACECOM) can provide additional tracking resources during the launch and early operations phase to determine the initial orbit of the spacecraft. This is particularly critical during launch so that if there is an abort the location of the reactor can be determined. The position tracking of the spacecraft can continue to be supported by the USSPACECOM for the life of the spacecraft. This can pose a unique problem with tracking since it is possible that the space nuclear reactor may be thrusting continuously by providing power to electric thrusters or if it is a $\mathrm{Bi}$ Modal reactor. The Air Force Satellite Control Network (AFSCN) can provide additional communication networks to allow communications (telemetry and commands) to/from the spacecraft during the life of the spacecraft.

\subsection{8}

\section{LAUNCH SITE SELECTION}

Another significant part of Mission Safety is the rationale for selection of the launch site. This is an important issue in the preparation of the Environmental Impact Statement and should be addressed early on in the program. Examples of factors for consideration of the launch site are:

1. Type of orbit is to a degree a function of the launch site and this in turn can affect the launch vehicle performance requirements which in turn can affect program cost. Launch site location can provide addition to boost velocity resulting from earth rotation thus reducing performance requirements on the launch vehicle.

2. Make maximum use of existing facilities which can support processing of nuclear material including contingency operations can hold down program costs. Some launch sites have been used in the past for Radioactive Thermoelectric Generator (RTG) powered spacecraft launches and have facilities which would support processing of a space nuclear reactor with minimum modifications. In addition there would be personnel available with experience in processing radioactive material based on previous RTG launches. 
3. Depending on the Mission requirements the launch site location may have to be able to support short term mission control center operations including telemetry uplink/downlink and processing of spacecraft tracking data from worldwide tracking systems.

4. Minimize flight over inhabited areas during boost phase to reduce risk of nuclear contamination in the event of launch abort.

NUCLEAR SAFETY

One of the previous nuclear space reactor programs had established a number of safety committees and working groups. The purpose of these safety committees was to ensure that the program met the Range, Local, State, and Federal safety requirements for processing, operation, and launch of the nuclear space reactor and the spacecraft and the associated launch vehicle. These safety committees are described in the following sub-sections and are offered as examples for consideration.

- $\quad$ NUCLEAR BI-WEEKLY FLIGHT SAFETY GROUP: Bi-weekly meetings were conducted to discuss significant flight safety topics and enhance communications in the program. The focus of these bi-weekly meetings was nuclear reactor flight safety to provide: feedback, promote team effort, and focus on Safety Assessment of Risk (SAR).

- INDEPENDENT NUCLEAR SAFETY ADVISORY COMMITTEE: The program manager received safety advice from an Independent Nuclear Safety Advisory Committee which was an independent body of experts which met quarterly to review nuclear system safety and provide top level safety advice to the program manager.

- DEPARTMENT OF ENERGY INDEPENDENT SAFETY ASSESSMENT: The Department of Energy conducted an independent safety assessment of the program. A review committee composed of several DOE personnel and nuclear experts from other organizations evaluated the design of the nuclear space reactor from a safety perspective.

- $\quad$ PROJECT SAFETY (Nuclear): The Project Manager for the nuclear reactor received safety advice from a small project safety team which performed independent checking of safety analysis.

A Preliminary Nuclear Safety Assessment (PSA) was conducted to provide an adequate nuclear safety assessment such that the sponsor could decide if a full-scale flight program should be initiated. The guideline was to perform an assessment sufficient to identify any important safety deficiencies and to suggest the type of modifications that might be required to eliminate these deficiencies. The next step was to proceed with the safety analysis to support the Interagency Nuclear Safety Review Panel (INSRP) process.

\subsubsection{INTERAGENCY NUCLEAR SAFETY REVIEW PANEL (INSRP)}

The INSRP is composed of five independent coordinators from National Aeronautics and Space Administration (NASA), Department of Defense (DoD), Environmental Protection Agency (EPA), Nuclear Regulatory Commission (NRC), and Department of Energy (DOE). Their function is to assess the radiological risk posed by the mission. As a result of their review they prepare a Nuclear 
Safety Evaluation Report (NSER) which is forwarded to the Office of Science and Technology Policy (OSTP) which can approve the mission for the President. The Interagency Nuclear Safety Review Panel (INSRP) is comprised of the following sub-panels: Launch Abort, Reentry, Meteorological, Power, and Medical/Environmental.

The INSRP process is illustrated in Figure 4. A Preliminary Safety Analysis Report (PSAR) is usually prepared 3 years prior to the mission. It addresses the mission, the power system, and risk. An Updated Safety Analysis Report (USAR) is provided to address the issues and is prepared a few years prior to the launch. A Final Safety Analysis Report (FSAR) is usually prepared 1 year before launch which contains the risk analysis. This report goes to the Interagency Nuclear Safety Review Panel (INSRP) which prepares the Nuclear Safety Evaluation Report (SER) which goes to Department of Defense (DoD) and Office of Science and Technology Policy (OSTP) requesting launch approval. The SER does not make the launch decision. It characterizes the level of risk and does not give direction on how to engineer the system. The SER looks at: the mission profile from arrival at the launch site to orbit, credible accidents which can occur, their effects, probability, and consequences, and the risk of release of radioactive materials in the biosphere. This information also becomes incorporated into contingency planning by the Lead Federal Agent (LFA) and the radiological protection officer at the launch site.

\section{FIGURE 4: SPACE NUCLEAR SAFETY REVIEW \& APPROVAL PROCESS}



(see articles an \& $\mathrm{z}$ in bibliography) 
An Environmental Impact Statement (EIS) to support decision making regarding preparation, testing, and launch of a spacecraft powered by space nuclear reactor must be in accordance with the legal, regulatory, and policy requirement of the National Environmental Policy Act (NEPA), the Council on Environmental Quality (CEQ), regulations implementing the National Environmental Policy Act (NEPA) (40CFR 1500-1508), Air Force Regulations (AFR) 19-2 and Department of Energy (DOE) Order 5440.1C. Preparation of this EIS is critical also to the range which requires a copy for their use in coordinating with local government agencies.

\section{6}

\section{INTERNATIONAL NUCLEAR SAFETY}

Nuclear safety guidelines are also recommended by United Nations Principle \#3 which essentially states that nuclear power sources in space shall be restricted to those space missions which cannot be operated by non-nuclear energy sources in a reasonable way. Principle \#3 also addresses SHO (sufficiently high orbit), criticality, zero power testing, re-entry, and radiation exposure. Other UN principles relating to space nuclear power address safety assessment (\#4), notification (\#2), responsibility (\#8), compensation (\#9), and disputes (\#10). At the time of this report a new proposal for launch requirements had been drafted (reference 13) and is being reviewed. This new proposal details launch site safety requirements and applies to every international organization and every entity participating in the activities carried out from a launch site. This new proposal specifies that radioactive elements remain completely enclosed whatever normal or accidental situations may arise during launch or re-entry process.

\section{SCHEDULING AND PLANNING}

The review and approval process combined with the requirements for certain documentation result in an overall schedule flow chart shown in Figure 5. A typical list of documentation used in support of nuclear safety is listed in Table 3.

The entire process to cover the safety aspects for Nuclear Safety, Range Safety, Range Operations, Orbital Safety, and Environmental Impact can take up to 5 years before launch approval. Since many of these areas, requirements, and documentation overlap close coordination is necessary to avoid duplication and insure that delays are not unnecessarily incurred.

The primary schedule driver is the INSRP process since the other areas, such as Range Safety, is very dependent on the products such as the Final Safety Analysis Report and the Safety Evaluation Report. It can take up to approximately 5 years from program start until Launch Approval is obtained. The Eastern and Western Ranges currently require the Environmental Impact Statement approximately 3 years from launch and the Final Safety Analysis Report approximately 2 years from launch. These schedule requirements are certainly program dependent and national need could certainly have an impact on the time requirements. Nonetheless early and close coordination with the Range is the most effective way to reduce delays and cost by insuring that designs and analyses, in addition to meeting the needs of the INSRP and EIAP processes, also meets Range Safety requirements.

\section{1}

\section{NUCLEAR SAFETY}

The INSRP process begins with a Preliminary Safety Analysis Report (PSAR) which is usually prepared 3 years prior to the mission and is developed soon after a design concept for the mission is developed. The PSAR describes the nuclear power source and the mission and also a probabilistic 
radiological risk assessment. The PSAR is based on information that is available at the time. The PSAR is followed by the Updated Safety Analysis Report (USAR). The USAR is issued after the power system design is frozen. The USAR updates the information on the mission description, radiological risk assessment, and failure modes analysis. The USAR also provides information relating to safety tests and required safety data. The Final Safety Assessment Report (FSAR) is usually issued about one to two years prior to launch and describes the final design of the nuclear power system, the mission, radiological safety assessment data, and contains reports of safety tests and the risk analysis. During this process the INSRP meets periodically to conduct reviews of the program. Upon completion of the FSAR the Interagency Nuclear Safety Review Panel prepares the Safety Evaluation Report (SER), characterizes the level of risk, and reports the results of the INSRP review and evaluation of the mission. Upon completion of the SER and its review and approval by other coordinating agencies (e.g. DOE, DoD, NASA) the SER is provided to the Office of Science and Technology Policy which is empowered to approve the launch by the President of the United States.

RANGE SAFETY AND RANGE OPERATIONS

In addition to kick-off of the INSRP process coordination with the selected range should be initiated. As soon as possible a Program Introduction document should be prepared and provided to the Range. The Program Introduction(PI) document is the initial planning document submitted by the program to the Range immediately upon identification of the scope and duration of program activity. Note that the PI is typically a requirement for DoD programs and not necessarily the same for nonDoD programs. For example NASA does not require a PI. The program should submit the PI using best available information, enabling the Range to initiate resource and technical planning. This information while sometimes fragmentary and incomplete, is of substantial value to the Range in determining the scope of the program. Upon receipt of the PI the Range will respond with a Statement of Capability (SOC). The SOC is evidence that a program has been accepted for support by the Range; subject to approval by higher headquarters, when applicable. Support conditions, qualifications and resources, or other considerations are initially identified by this document and serve as a baseline reference to subsequent acceptance and commitment by the Range. The PI and the SOC complement each other in establishing the scope of the program support activity. Following the PI and SOC the program should prepare the Program Requirements Document (PRD). The PRD is a detailed full program planning document normally required for complex or long leadtime programs. The PRD contains the requirements for support desired from the Range and may contain supplemental information when needed for clarity of purpose. A PRD is submitted to assure that support capability will be available during the time period required by the user organization. Requirements should be submitted immediately upon identification. The program should not delay submittal of the PRD because of incomplete knowledge of support requirements. For a nuclear space reactor program there will be extensive requirements that need to be identified in the PRD such as building facilities, tracking aircraft, security, etc. In addition to the PRD the program will prepare Operations Requirements (ORs) which is a mission oriented document that describes in detail the requirements for each mission, special test, or series of tests. The PRD and OR must be complete documents capable of standing alone and the OR must not reflect new requirements not previously stated in the PI and/or PRD. In response to the ORs the Range will prepare Operations Directives (ODs) which is the detailed plan for implementation of support functions for a specific test or series of tests. One of the major documents required by the Range is the Missile Systems Prelaunch Safety Package (MSPSP). The Missile Systems Prelaunch Safety Package contains a detailed description of the design, test, and inspection requirements for all ground support equipment and flight hardware and materials and their interfaces used in the launch of launch vehicles and their payloads. It is one of the principle documents through which missile system prelaunch safety approval from the ranges is obtained. 
In addition to interfaces with the Range regarding range safety there are requirements for orbital safety. The necessary orbital safety documentation required to resolve orbital safety issues is generally developed in accordance with the USSPACECOM and the Consolidated Space Test Center (CSTC) requirements or NASA depending on whether the mission is DoD or non-DoD. Note that at the time of this report CSTC was in the process of being renamed and the relationship with other Air Force organizations was being addressed. All systems with nuclear power systems must have a review of re-entry risk assessment and the nuclear safety program must be conducted in accordance with MIL-STD-1574 (System Safety Program for Space and Missile Systems). One of the principal documents regarding orbital safety is the Test Operation Risk Assessment (TORA). The TORA presents a general overview of the purpose, scope and test mission including: program name, office of responsibility, general description of the vehicle, and orbital operations (sequence of events and corresponding timeline). The TORA also states the number and designation of tests, objectives, and dates. Other items also detailed are data retrieval, communications, schedule, test procedures, tracking aids (e.g. special test data reception, hardware, displays, and related software requirements). The TORA also presents orbital data (e.g. state vector, apogee, perigee, inclination, maneuver requirements). The TORA also contains enough information (category and severity) for each hazard category to allow an independent reviewer to make an intelligent, analytical verification of risk. The program also has to supply a Preliminary Hazard List (PHL). The PHL is generated early in the conceptual phase and from this list a preliminary hazard analysis is performed in accordance with MILSTD-882B (defines requirements for a system safety program). This analysis is a first review of hazardous conditions presented during system reviews and test planning, recognizing only minimum information is available on design detail, and only conceptual ideas on test operations. This analysis provides a beginning for analysis and planning and should determine what hazards will exist during test operations, the cause and effect, and recommended controls. Using results of the analysis, a Hazard Report is initiated on each space-safety hazard, and a Hazard Log is initiated and maintained on the hazards. This report and log should be provided to CSTC Safety so they may monitor the status of space-safety hazards. CSTC Safety, using the Hazard Log, implements their own log on space-related hazards; therefore, any changes in status should be provided to them. After all spacesafety testing requirements have been satisfied and an independent assessment of the test mission has been successfully accomplished, the Test Operations Space Safety Approval (TOSSA) will be issued by the CSTC Commander. The approval signifies that the CSTC has concluded that planned space and space-related testing is acceptable or properly controlled as necessary. It may identify any safety constraints on test support and may specify conditions of approval. If conditions are specified, these conditions must be satisfied prior to final acceptance. During the interaction with CSTC there are various safety reviews. The Orbital Readiness Space Safety Review (ORSSR) is conducted by CSTC Safety primarily to ensure that safety support readiness is at a level where it can support rehearsals.

\section{4}

\section{ENVIRONMENTAL IMPACT}

The Environmental Impact Assessment Process (EIAP) begins with filing of a Notice of Intent (NOI) which is a public record of intent to launch a nuclear powered system. Following this is development of the Environmental Impact Statement (EIS) which goes through a succession of drafts and reviews. Upon completion of the EIS a Notice of Availability (NOA) is issued which allows the public to obtain and review the EIS. After acceptance of the EIS there is a Record of Decision (ROD) which documents the acceptance of the EIS. The Range requires the EIS approximately three years prior to launch so that local authorities and local governments associated with the Range can be properly notified and informed of the risk and impact of the launch of a nuclear powered system. In addition a Lead Federal Agent needs to be identified which is the agency that owns and operates the payload including the reactor. 
FIGURE 5: NOMINAL SAFETY REVIEW AND APPROVAL SCHEDULE

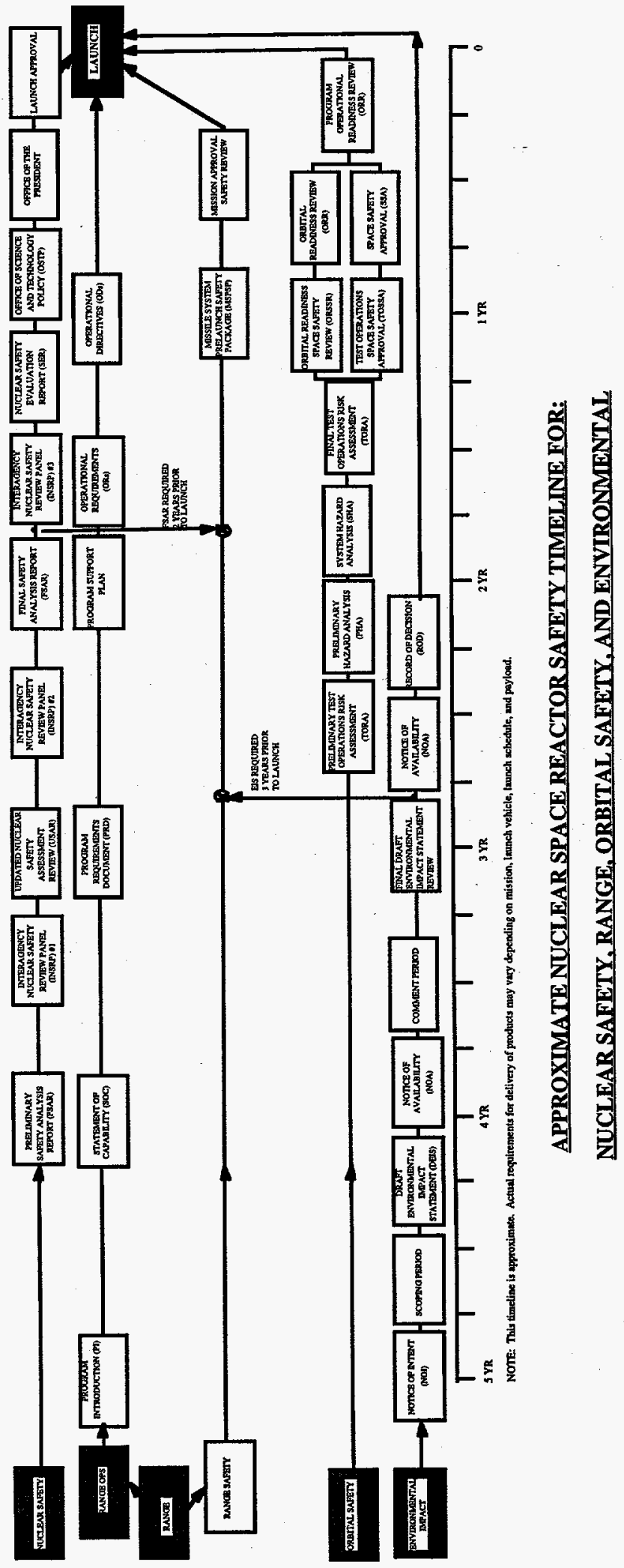


TABLE 4: TYPICAL LIST OF NUCLEAR SAFETY RELATED DOCUMENTS

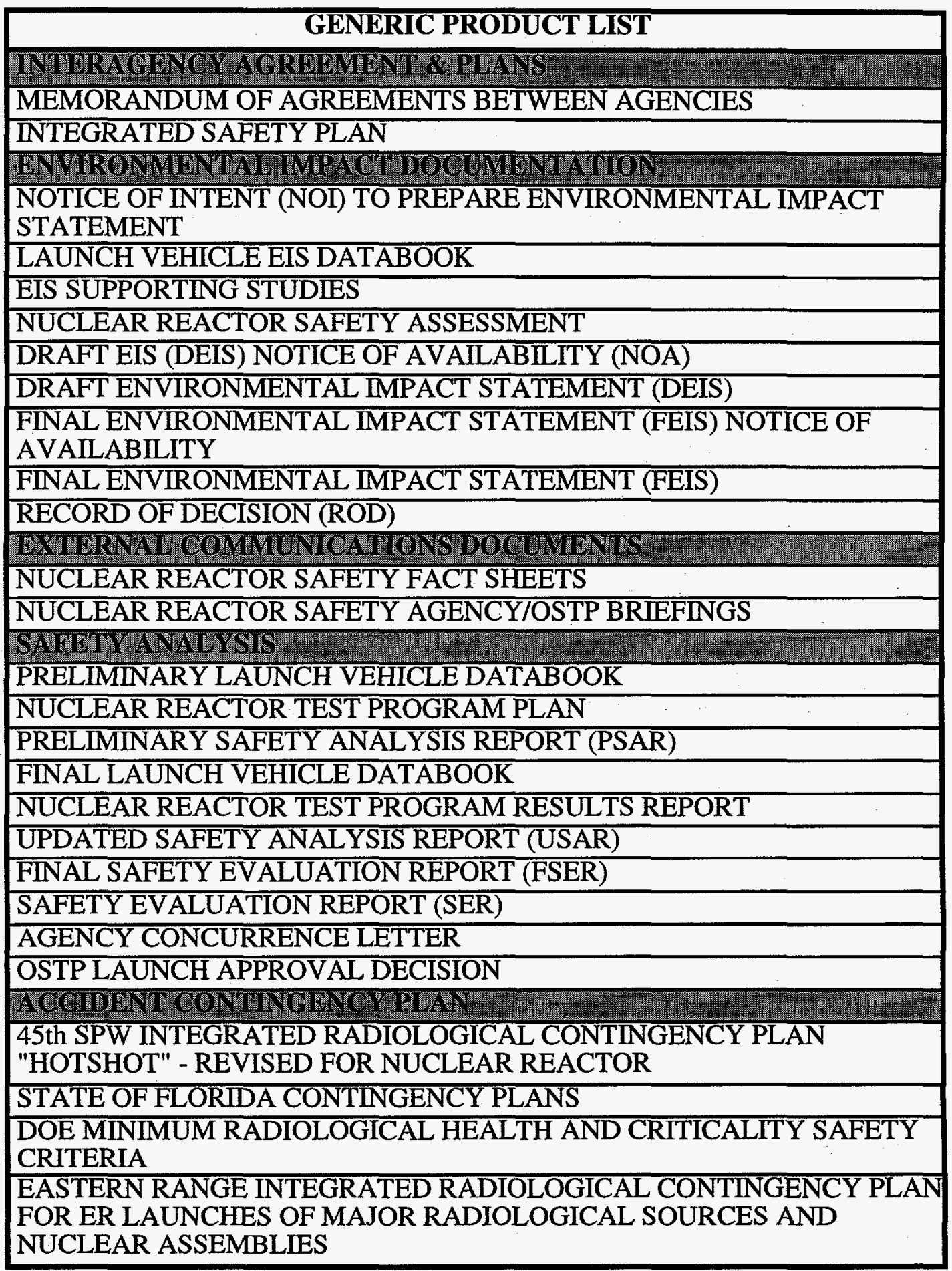


Currently safety requirements for nuclear space powered missions are based on RTGs. The differences between space nuclear power systems and RTG devices are sufficient that safety and facility requirements warrant a review in the context of the unique features of a space nuclear reactor power system. This report has addressed safety guidelines for use by future planners of nuclear powered space missions, including Bi-Modal nuclear propulsion, in the areas of range safety, range facilities, mission safety, and nuclear safety.

A summary of the guidelines in these areas is:

\section{COORDINATION}

- Develop an integrated program safety plan whose purpose is to provide a document which serves to coordinate the various safety activities in Mission Safety, Range Safety, and Nuclear Safety.

\section{RANGE SAFETY \& FACILITIES}

- The range requirements need to be examined in the context of a space nuclear reactor and guidelines proposed so that additional costs and design constraints are not imposed unnecessarily and so that unique safety requirements for nuclear space reactors are addressed.

- There are no specific requirements defined for facilities for nuclear space reactors. All requirements are currently based on RTGs. One of the areas which would have to be reviewed as part of a nuclear space reactor program is the facility requirement.

- A recommendation is made for no Zero Power Testing of the nuclear reactor at the launch site. Performing a Zero Power Test would necessitate such things as: additional monitoring equipment, additional monitoring crews, location of the reactor in a low populated/remote site on the range, evacuation of personnel from the area, additional requirements of security of the building, and additional requirements on the building to run at negative pressure. Another approach is to assume fueling at the launch site and more than a zero power test. This is a conservative assumption to preclude a situation where that might be "last minute" design changes which could result in facing an insurmountable engineering problem or run into a difficult safety issue.

- An important distinction needs to be made regarding contingency plans which previously addressed RTGs which have much higher toxicity and radioactivity than space nuclear reactors (assuming that they have not yet gone critical before launch). This contingency planning for launch of a space nuclear reactor needs to account for this difference which can affect the level of radiation monitoring equipment and teams and surveillance aircraft required.

- Regarding transportation of the reactor and fuel to the launch site one approach which has merit is to deliver the nuclear reactor fuel elements to the launch site. This approach can reduce logistics complexity and cost of a special shipping cask for shipping a fueled reactor. 
- Early coordination between the launch vehicle contractor, range safety officers, and safety representatives from the space nuclear reactor program is recommended to identify potential safety concerns early in the program and to minimize any cost or schedule impact

- One of the requirements noted for RTGs is the use of an underwater acoustic beacon for assistance in recovery of the radioactive material. A similar requirement would probably be appropriate for a space nuclear reactor but more from the point of view of recovery of weapons grade nuclear material rather than because of radioactivity or toxicity risks.

- A nuclear reactor may contain toxic substances for moderator materials and for radiation shielding. Information concerning personnel risk and procedures for proper handling of these materials need to be provided to the range.

\section{MISSION SAFETY}

- A desirable objective of the mission is to launch into sufficiently high orbit such that the fission product inventory has had time to decay to the level of the actinides prior to reentry. Some thought must be given as to whether this should be a requirement or a guideline. If it is a requirement then some missions may be precluded if they need to be closer to earth in order to meet the mission objectives.

- One of the areas which needs to be addressed is the event of a radiological release to the space environment which is related to U.S. space policy which is intended to minimize space debris.

- The flight over inhabited areas during boost phase should be minimized if possible to reduce risk of nuclear contamination in the event of launch abort.

- One area which should be examined is interference with other satellite operations. Emission of gamma rays, for example, as a result of reactor operation could interfere with scientific instruments on other satellites.

- The need for a plan for shut-down of the space nuclear reactor at the end of the useful life of the reactor should be considered.

- Radar tracking and telemetry is desirable to monitor separation of the spacecraft, with its nuclear reactor, from the launch vehicle and to monitor reactor startup sequence. Continuous tracking and projection of orbit may be necessary in the event the spacecraft is continuously thrusting (e.g. using nuclear power for electric thrusters to attain higher orbit).

\section{NUCLEAR SAFETY}

- At present there is still the requirement for programs which launch radiological material into space to prepare safety analysis reports which are reviewed by the Interagency Nuclear Safety Review Panel (INSRP). These safety reports and results of the INRSP should be made available to the range and it is also recommended that a range representative be part of the INSRP process.

\section{SCHEDULING AND PLANNING}

One of the more significant considerations is the length of time it could take to prepare the analysis, safety reports, environmental studies, and obtain approvals for launch of a nuclear space reactor. If all currently known requirements for documentation (e.g. lead time for environmental impact statements) are followed it could conceivably take up to 5 years to obtain launch approval. However it should be noted that: (1) current requirements are those for RTGs and may not be the same for nuclear reactors and (2), national interests may impact these requirements either by decreasing or maybe even increasing the time required. 


\begin{tabular}{|c|c|}
\hline $\begin{array}{l}\text { GLOSSARY } \\
A F\end{array}$ & Air Force \\
\hline $\begin{array}{l}\text { AF } \\
\text { AFR }\end{array}$ & $\begin{array}{l}\text { Alr Force } \\
\text { Air Force Regulations }\end{array}$ \\
\hline AFSCN & Air Force Satellite Control Network \\
\hline $\mathrm{B}_{4} \mathrm{C}$ & Boron Carbide \\
\hline $\mathrm{Be}^{4}$ & Beryllium \\
\hline BMDO & Ballistic Missile Defense Office \\
\hline CCAFS & Cape Canaveral Air Force Station \\
\hline & Cesium \\
\hline CSTC & Consolidated Space Test Center \\
\hline DoD & Department of Defense \\
\hline DOE & Department of Energy \\
\hline EIAP & Environmental Impact Assessment Process \\
\hline EIS & Environmental Impact Statement \\
\hline EM & Electromagnetic Pump \\
\hline EPA & Environmental Protection Agency \\
\hline ESMC & Eastern Space and Missile Center \\
\hline FSAR & Final Safety Assessment Report \\
\hline HEPA & High Efficiency Particulate Air \\
\hline INSRP & Interagency Nuclear Safety Review Panel \\
\hline IPSP & Integrated Program Safety Plan \\
\hline KSC & Kennedy Space Center \\
\hline $\mathrm{kW}$ & Kilowatt \\
\hline $\mathrm{LiH}$ & Lithium Hydride \\
\hline MOA & Memorandum of Agreement \\
\hline MSPSP & Missile Systems Prelaunch Safety Package \\
\hline $\mathrm{NaK}$ & Sodium-Potassium \\
\hline NEPSTP & Nuclear Electric Propulsion Space Test Program \\
\hline NOA & Notice of Availability \\
\hline NOI & Notice of Intent \\
\hline NRC & Nuclear Regulatory Commission \\
\hline${ }^{\circ} \mathrm{C}$ & Degrees Centigrade \\
\hline OD & Operations Directives \\
\hline OR & Operations Requirements \\
\hline ORSSA & Orbital Readiness Space Safety Assessment \\
\hline OSTP & Office of Science and Technology Policy \\
\hline PHL & Preliminary Hazard List \\
\hline PI & Program Introduction \\
\hline PRD & Program Requirements Document \\
\hline PSAR & Preliminary Safety Analysis Report \\
\hline RADCC & Radiation Control Center \\
\hline ROD & Record of Decision \\
\hline RTG & Radioisotope Thermoelectric Generator \\
\hline SER & Safety Evaluation Report \\
\hline SHO & Sufficiently High Orbit \\
\hline SNM & Special Nuclear Material \\
\hline SOC & Statement of Capability \\
\hline SPW & Space Wing \\
\hline TFE & Thermionic Fuel Element \\
\hline TORA & Test Operation Risk Assessment \\
\hline TOSSA & Test Operations Space Safety Approval \\
\hline USAR & Updated Safety Analysis Report \\
\hline USSPACE & United States Space Command \\
\hline
\end{tabular}


Zirconium Hydride

(1)




\section{REFERENCES}

1 DOE Order 5633.3A (Draft)

2 DOE/OSD Memorandum "Minimum Radiological Health and Criticality Safety Criteria" $1 / 28 / 82$

3 ESMC 160-1 "Radiation Protection Program", change 1, 10/22/85

4 ESMC S-Plan 28-74 "Major Radiological Source Support (HOT SHOT)" revision \#1, 8/7/90

5 EWR 127-1 "Range Safety", 3/31/95

6 DOE Order 5634.1B Facility Approvals, Security Surveys, and Nuclear Materials Surveys

7 DoD Manual 5210.41, "Nuclear Weapons Security"

8 AFI 31-101 (draft), "Instructions for the Air Force Physical Security"

9 "NEPSTP Nuclear Safety Policy, Functional Requirements and Safety Guidelines Document"

10 "Impact of the Use of Low or Medium Enriched Uranium on the Masses of Space Nuclear Reactor Power Systems", DOE report DOE/NE-0112, December 1994

11 "Space Safety Users Handbook", Consolidated Space Test Center, Onizuka Air Force Base, 19 November 1991

12 "Nuclear Safety Review and Approval Procedures for Minor Radioactive Sources in Space", National Aeronautics and Space Council, 16 June 1970

13 ISO Standard (Working Draft - 14620), "Space Systems-Launch Site Operations Safety Requirements", March 30, 1995

14 Code of Federal Regulations, 1 January 1990, Part 20, Appendix C - quantities of radioisotopes exempt from control

15 "Nuclear Safety Review and Launch Approval for Space or Missile Use of Radioactive Material and Nuclear Systems", Air Force Regulation 122-16, 21 August 1992 (note: this is being reissued as an Air Force Instruction but the title is the same)

16 "Facilities Handbook for Radioisotope Thermoelectric Generator Storage Building", K-STSM14.1.8, December 1987 Revision B (include chg. 1)

17 Federal Register: Federal Emergency Management Agency, Vol. \#50, No. 217, pages 4654246551, 8 November 1985

18 KHB 1860.1A Appendix D Annex D-2 Integrated Radiological Contingency Plan for KSC Launches of Major Radiological Sources and Nuclear Assemblies

19 KHB 1860.1B KSC Ionizing Radiation Protection Program 


\section{BIBLIOGRAPHY}

a An Analysis of thermionic Space Nuclear reactor Power System: Effect of Disassembling Radial Reflector, Following a Reactivity Initiated Accident; Mohamed S. El-Genk and Dmitry Paramonov; Conference 930103 American Institute of Physics 1993

b An Analysis of Thermionic Space Nuclear Reactor Power System: Merits of Using Safety drums for Backup Control; Mohamed S. El-Genk and Huimin Xue; Conference 930103 American Institute of Physics 1993

c An Assessment of the United Nations Principles on the Use of Nuclear Power Sources in Outer Space; N. Jasentuliyana; American Institute of Aeronautics and Astronautics 1993

d Applicability of Trends in Nuclear safety Analysis to Space Nuclear Power Systems; Robert A. Bari; Conference 930103 American Institute of Physics 1993

e Are the Principles on the Use of Nuclear Power sources in Outer Space a Progress in Space Law; Aldo Armando Cocca; American Institute of Aeronautics and Astronautics; 1993

f Code of Federal Regulations; Office of the Federal Register National Archives and Records Administration; 1-Jan-90

g Control of Radioactive Material; Department of the Air Force; 16-Dec-88; AFR 161-16

h Draft environmental Concept Study: Nuclear Electric Propulsion Space Test Program; Air Force Center for Environmental Excellence; Jun-93

i Draft Environmental Impact Statement for the Cassini Mission; Solar System Exploration Division, Office of Space Science, NASA; Oct-94

j Draft Principles on Nuclear Power Recommended to Assembly; UN Chronicle; Sep-92

k Evolution of space Reactor Safety; Joseph R. Wetch; Conference 930103 American Institute of Physics 1993

1 Facilities Handbook for Radioisotope thermoelectric Generator Storage Building; NASA; Dec-89; K-STSM-14.1.8 Revision B

m Facility Approvals, Security Surveys, and Nuclear Materials Surveys; Department of Energy; 15-Sep-92; DOE 5634.1B

n Federal Emergency Management Agency; FEDERAL REGISTER; 8-Nov-85

o International responsibility for Using Nuclear Power Sources in Outer Space - Reflections on the Text Adopted by Copous; Andrei D. Tarekhova; American Institute of Aeronautics and Astronautics; 1991

p Major radiological Source Support (Hot Shot); Eastern Space and Missile Center; 7-Aug90; ESMC S-Plan 28-74

q Minimum Radiological Health and Criticality Safety Criteria; Department of Energy, Albuquerque Operations Office

NEP Space Test Program Preliminary Nuclear Safety Assessment (Second Draft); U.S. 
Topaz II Flight Safety Team; P.O.C. Albert C. Marshall; 10/1/92

s NEPSTEP Nuclear Safety Policy, Functional Requirements and Safety Guidelines Document; P.O.C. Albert C. Marshall; 28-Apr-93

t Nuclear Accidents on Space Objects with Nuclear Power Sources: Applicable International Law; E. Molodtsova; American Institute of Aeronautics and Astronautics; 1991

u Nuclear Power Sources in Space: A Historical Review; John W. Lawrence; Nuclear News; Nov-91

v Nuclear Power system Safety reviews and Surveys; Department of the Air Force; 24-Feb78; AFR 122-15

w Nuclear safety Assurance for Space Thermionic Reactor with Positive Temperature Effect; Nikolai N. Ponomaarev-Stepnoi, Yevgeniy S. Glushkov, Georgiy V. Kompaniets, Vyacheslav A. Lobyntsev, Valdimir V. Skorlygin; Conference 930103 American Institute of Physics 1993

x Nuclear safety Review and Approval Procedures for Minor Radioactive Sources in Space; Executive Office of the President, National Aeronautics and Space Council; 16-Jun-70

y Nuclear Safety Review and Launch Approval for Space or Missile Use of Radioactive Material and Nuclear Systems; Department of the Air Force; 24-Aug-92; AFR 122-16

z Perspective of the Interagency Nuclear Safety Review Panel (INSRP) on Future Powered Space Missions; Leven B. Gray, David W. Pyatt, Joseph A. Shlotis, Robert O. Winchester; Conference 930103 American Institute of Physics 1993

aa Promise Assessment: A Corollary to Risk Assessment for Characteristic Benefits; Joseph A. Sholtis; Conference 930103 American Institute of Physics 1993

$\mathrm{ab}$

Protection Program Operations (PPO); Department of Energy; DOE 5632.1A

ac Radiation Protection Program; Department of the Air Force; 22-Oct-85; ESMCR 160-1

ad Radionuclide Inventories for Short Run-Time Space Nuclear Reactor Systems; Richard L. Coats; Conference 930103 American Institute of Physics 1993

ae Requirements for the Protection of Special Nuclear Materials and Vital equipment (DRAFT); Department of Energy; DOE 5633.3A (Draft)

af Safety and environmental Analysis for Space Nuclear Programs; D. J. McConnell; Space Power, Vol. 9, No. 1; 1990

ag Significance and Implementation of Particle Size, 3-D Wind, and Process Timing in a Space Accident radiological Transport Model; Chuong T. Ha and Dennis R. Damon; Conference 930103 American Institute of Physics 1993

ah SP-100 Flight Safety Analysis; Mark I. Temme, Neil W. Brown, and Michael A. Smith; Conference 930103 American Institute of Physics 1993

ai Space Nuclear Power and the UN; Steven Aftergood; Space Policy; Feb-92 
aj Space Reactor Power System Nuclear Safety; N.W. Brown, D.R. Damon, M.A. Smith, and M.I. Temme; Nuclear Safety, Vol 31, No. 4; October - December 1990

ak Technical Note: The Interagency Nuclear Safety Review Panel's Evaluation of the Ullysses Space Mission; J.A. Sholtis Jr., D. A. Huff, L. B. Gray, N. P. Klug, and R. D. Winchester; Nuclear Safety, Vol. 32, No. 4; October - December 1991

al The Problem of Space Nuclear Power Sources Collisions with Artificial Space Objects in Near-Earth Orbits; Albert A. Gafarov; Conference 930103 American Institute of Physics 1993

am The Risks of Using Nuclear Energy Sources in Space: Some Lay Activists' Perceptions; Michael Maharik and Barusch Fischhoff; Risk Analysis, Vol. 12, No. 3; 1992

The Safety Review and Approval Process for Space Nuclear Power Sources; Gary L. Bennett; Nuclear Safety, Vol. 32, No. 1; January - March 1991

The Use of Nuclear Power Sources in Outer Space: A new Set of United Nations

Principles?; Dr. Vladimir Kopal; American Institute of Aeronautics and Astronautics; 1990

TOPAZ II Preliminary Safety Assessment; Albert C. Marshall, Susan S. Voss, Vaughan

Standley, Eric Haskin; Conference 930103 American Institute of Physics 1993

TOPAZ-2 Nuclear Safety Analysis for Water Immersion; Nikolai N. Ponomaarev-Stepnoi, Vladimir G. Bubelev, Yevgeniy S. Glushkov, Victor Ye. demin, Georgiy V. Kompaniets, Gennadiy V. Lebedev, Vyacheslav A. Lobyntsev, Yuriy A. Nechaev, Yevgeniy I. Chunyaev; Conference 930103 American Institute of Physics 1993

ar Atomic Energy Commission Report on Aerospace Nuclear Safety, AEC 1051/2, October 4, 1960 , Provides a current evaluation of the safety aspects of aerospace nuclear propulsion and power devices that are being developed by the Division of Reactor Development (*)

as Aerospace Nuclear Safety, Donald M. Ross, Office of Health and Safety, U.S. Atomic Energy Commission, presented June 30,1960 at the 5th Annual Meeting of the Health Physics Society in Boston, Massachusetts (*)

at Space Nuclear Reactor Safety, Mechanical Engineering, November 1963 (*)

au Aerospace Nuclear Safety Program, W.K. Kern and G. B. Connor, Nuclear Safety, March 1963, Volume 4 Number $3\left(^{*}\right)$

av Some Fundamental Characteristics of the Safety Problems Associated with the Orbital Operation of Nuclear Rockets, Ralph S. Decker, Atomic Energy Commission, January 10, $1963\left(^{*}\right)$

aw Plans and Specifications for the RIFT Safety Review Program, Atomic energy Commission, Space Nuclear Propulsion Office, October 1, $1962(*)$ 
az Meeting with DRD Safety Personnel at Germantown, Feb. 7, 1962, Atomic Energy Commission memorandum $\left({ }^{*}\right)$

ba SNAP Nuclear Reactors, Atomic Energy Commission pamphlet September $1966\left(^{*}\right)$

* Material written in the 1960s and obtained from search of DOE files on world- wide-web (http://www.doe.gov/html/doe/infolink/infolink.html) and copies requested from DOE/NV Coordination and Information Center, P.O. Box 98521, Las Vegas, NV 89193-8521 